\title{
Reviews
}

Carbon Dioxide Capture

\section{Carbon Dioxide Capture: Prospects for New Materials}

Deanna M. D'Alessandro, * Berend Smit,* and Jeffrey R. Long*

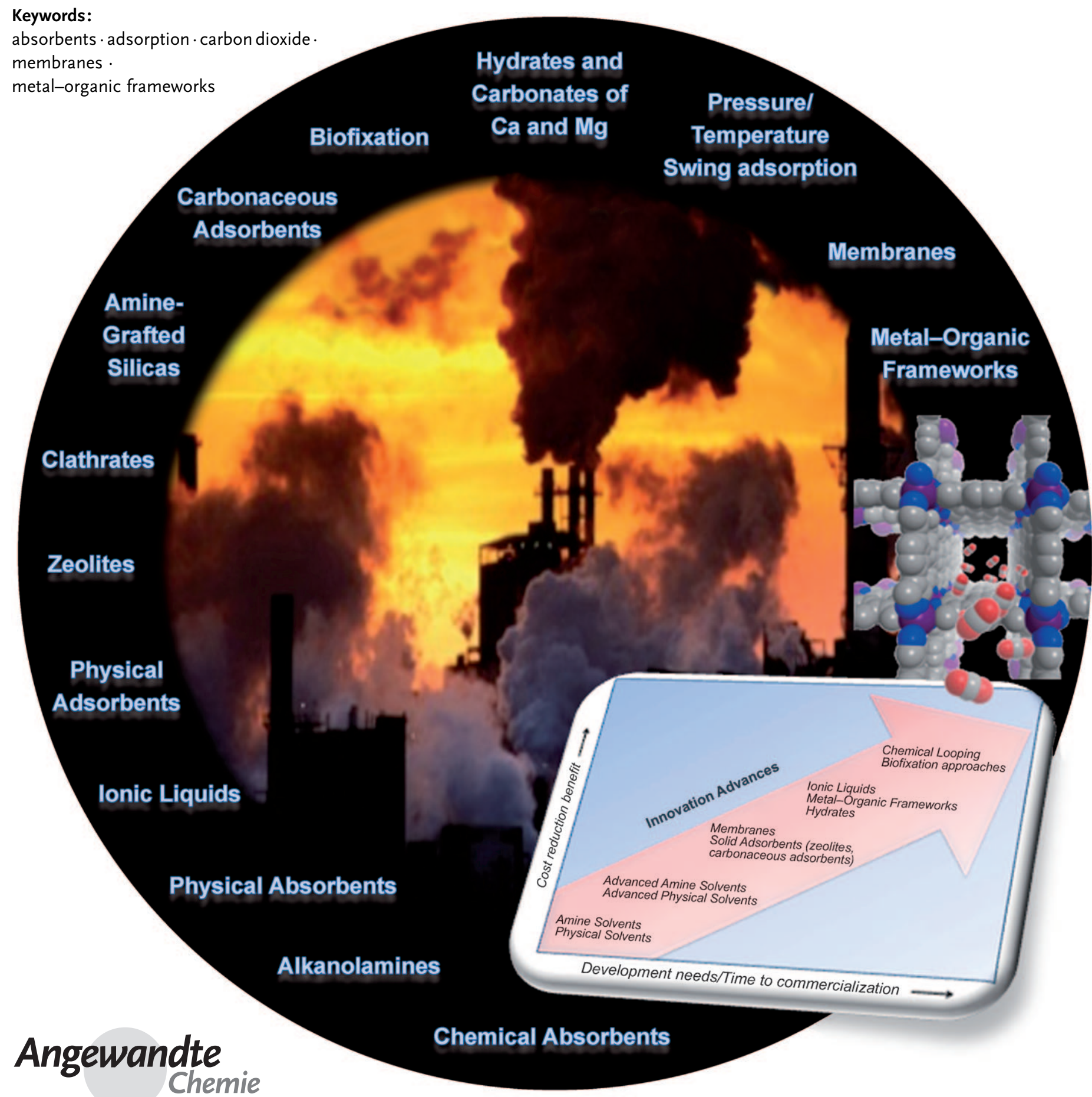


$T_{h}$ pressing environmental concerns of our age. Carbon capture and storage (CCS) from large point sources such as power plants is one option for reducing anthropogenic $\mathrm{CO}_{2}$ emissions; however, currently the capture alone will increase the energy requirements of a plant by $25-40 \%$. This Review highlights the challenges for capture technologies which have the greatest likelihood of reducing $\mathrm{CO}_{2}$ emissions to the atmosphere, namely postcombustion (predominantly $\mathrm{CO}_{2} / \mathrm{N}_{2}$ separation), precombustion $\left(\mathrm{CO}_{2} / \mathrm{H}_{2}\right)$ capture, and natural gas sweetening $\left(\mathrm{CO}_{2} / \mathrm{CH}_{4}\right)$. The key factor which underlies significant advancements lies in improved materials that perform the separations. In this regard, the most recent developments and emerging concepts in $\mathrm{CO}_{2}$ separations by solvent absorption, chemical and physical adsorption, and membranes, amongst others, will be discussed, with particular attention on progress in the burgeoning field of metalorganic frameworks.

\section{From the Contents}

\begin{tabular}{l} 
1. Introduction \\
$\begin{array}{l}\text { 2. Conventional Chemical } \\
\text { Absorption }\end{array}$ \\
$\begin{array}{l}\text { 3. Emerging Methods for } \mathrm{CO}_{2} \\
\text { Capture }\end{array}$ \\
$\begin{array}{l}\text { 4. New Materials for } \mathrm{CO}_{2} \text { Capture } \\
\text { 5. Future Prospects }\end{array} 60606$ \\
\hline
\end{tabular}

\section{Introduction}

The prospect of a worsening climatic situation due to global warming is a subject of widespread public concern, with annual global emissions of $\mathrm{CO}_{2}$ having escalated by approximately $80 \%$ between 1970 and 2004. ${ }^{[1]}$ This drastic rise has been attributed to an increasing dependence on the combustion of fossil fuels (coal, petroleum, and natural gas) which account for $86 \%$ of anthropogenic greenhouse gas emissions, the remainder arising from land use change (primarily deforestation) and chemical processing. ${ }^{[2]}$

The urgent need for strategies to reduce global atmospheric concentrations of greenhouse gases has prompted action from national and international governments and industries, and a number of high-profile collaborative programs have been established including the Intergovernmental Panel on Climate Change (IPCC), the United Nations Framework Commission on Climate Change, and the Global Climate Change Initiative. The capture and sequestration of carbon dioxide-the predominant greenhouse gas-is a central strategy in these initiatives, as it offers the opportunity to meet increasing demands for fossil fuel energy in the short- to medium-term, whilst reducing the associated greenhouse gas emissions in line with global targets. ${ }^{[3]}$ Carbon capture and storage (CCS) schemes embody a group of technologies for the capture of $\mathrm{CO}_{2}$ from power plants, followed by compression, transport, and permanent storage. CCS will complement other crucial strategies, such as improving energy efficiency, switching to less carbon-intensive fuels such as natural gas and phasing in the use of renewable energy resources (e.g., solar energy, wind, and biomass).

A critical point is that the deployment of CCS schemes is a multifaceted problem that requires shared vision and worldwide collaborative efforts from governments, policy makers and economists, as well as scientists, engineers and venture capitalists. From this perspective, it is apparent why the problem of $\mathrm{CO}_{2}$ capture is regarded as one of the grand challenges for the 21 st century. ${ }^{[3]}$

A number of recent high-profile reports and comprehensive articles have considered the engineering feasibility and economics of $\mathrm{CO}_{2}$ capture, and have sought to estimate the costs by modeling reference cases of existing postcombustion capture in coal- and gas-fired power plants. ${ }^{[3-5]}$ Such conventional technologies for large-scale capture have been commercially available for over 50 years and are focused on the separation of $\mathrm{CO}_{2}$ from flue gases by the use of amine absorbers ("scrubbers") and cryogenic coolers. ${ }^{[6]}$

The IPCC estimates that $\mathrm{CO}_{2}$ emissions to the atmosphere could be reduced by $80-90 \%$ for a modern conventional power plant equipped with carbon capture and storage technology. ${ }^{[7]}$ A recent analysis has shown that the thermodynamic minimum energy penalty for capturing $90 \%$ of the $\mathrm{CO}_{2}$ from the flue gas of a typical coal-fired power plant is approximately $3.5 \%$ (assuming a flue gas containing $12-15 \%$ $\mathrm{CO}_{2}$ at $\left.40{ }^{\circ} \mathrm{C}\right) \cdot{ }^{[8]}$ By comparison, conventional $\mathrm{CO}_{2}$ capture using amine scrubbers will increase the energy requirements

[*] Dr. D. M. D’Alessandro

School of Chemistry, The University of Sydney

Sydney, New South Wales 2006 (Australien)

E-mail: deanna@chem.usyd.edu.au

Prof. B. Smit

Department of Chemical Engineering

University of California, Berkeley

Berkeley, CA 94720-1460 (USA)

E-mail: Berend-Smit@berkeley.edu

Prof. B. Smit, Prof. J. R. Long

Department of Chemistry

University of California, Berkeley

Berkeley, CA 94720-1460 (USA)

Fax: $(+1)$ 510-643-3546

E-mail: jrlong@berkeley.edu 
of a plant by $25-40 \% \cdot .^{[7-9]}$ Other recent cost analysis estimates based on near-term conventional regenerative amine scrubbing systems have predicted an increased cost of electricity of $\$ 0.06 \mathrm{kWh}$, or an "avoided cost of capture" of \$57-60/tonne $\mathrm{CO}_{2}$ (as an alternative measure). ${ }^{[8]}$ Clearly, the existing methods of capture are energy intensive and are not costeffective for carbon emissions reduction. ${ }^{[7]}$ These economic and energy comparisons underscore the immense opportunities and incentives that exist for improved $\mathrm{CO}_{2}$ capture processes and materials.

Various components of the CCS process chain including compression, transportation (by pre-existing pipelines for instance), and storage of $\mathrm{CO}_{2}$ are technologically mature and available, and a growing number of fully integrated CCS projects are reaching the pilot and demonstration phases prior to commercialization. In addition to three large-scale demonstration projects which are currently underway in Sleipner West (Norway), Weyburn (Canada), and In Salah (Algeria), several smaller projects have commenced on the Dutch continental shelf (Netherlands), Snøhvit (Norway), La Barge (Wyoming, United States), Fenn Big Valley (Canada), Ketzin (Germany), and Schwarze Pumpe (Germany). ${ }^{[9-11]}$ All of the current projects demonstrate carbon storage or reuse in enhanced coal-bed methane recovery schemes, although one project at Schwarze Pumpe in Germany, captures $\mathrm{CO}_{2}$ at a coal-based plant. A further $40 \mathrm{CCS}$ projects have already been proposed worldwide between 2008 and 2020. ${ }^{[1]}$

One explanation for the slow deployment of fully integrated commercial CCS schemes is the considerable cost of the capture phase, which represents approximately two thirds of the total cost for CCS. A recent comprehensive report on postcombustion $\mathrm{CO}_{2}$ capture technologies has determined that the regeneration energy, followed by the capital cost of capture-specific equipment are the two variables contributing most significantly to the cost of $\mathrm{CO}_{2}$ capture. ${ }^{[8]}$ One significant contributor to the regeneration energy is the maximum separation efficiency which can be achieved by a given capture material. Enhancing this efficiency will have the greatest potential for lowering the overall cost of capture systems in near-term, ${ }^{[8]}$ with improvements in the capture phase for new materials representing one of the foremost challenges. ${ }^{[5]}$ As shown in Figure 1, there exists a serious need for research on innovative new materials in order to reduce the time to commercialization.

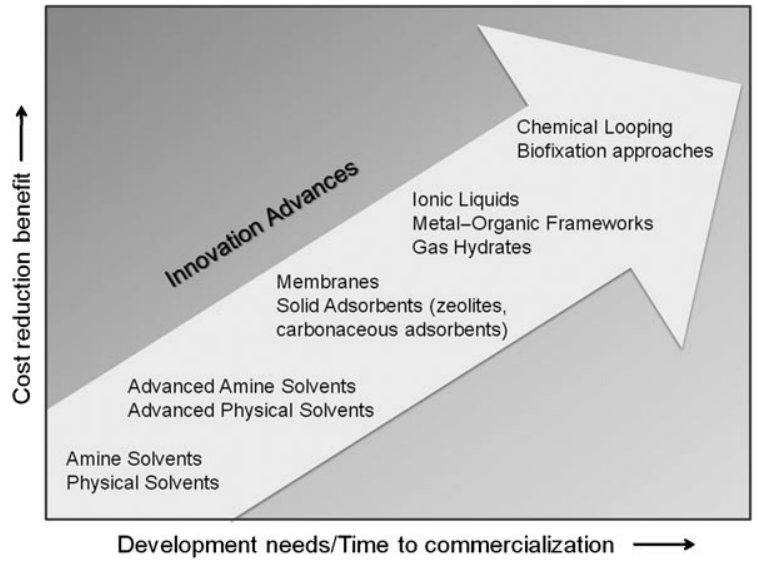

Figure 1. Innovative concepts in $\mathrm{CO}_{2}$ capture and their cost reduction benefits versus their remaining development needs/time to commercialization..$^{[5,12]}$

It is evident that a consideration of the process design economics and costs are required to assess fully the potential of any given new material. The challenge arises due to necessary assumptions which must be made, and the variations in the technical characteristics (e.g. fuel used, plant characteristics), scale and application of a given material, which require that capital costs be balanced with the efficiency of material. Assessing the economics of CCS is a nontrivial task which is outside the scope of the present article. Nevertheless, a number of groups have developed advanced cost-analysis models, which permit a number of the aforementioned parameters to be varied. ${ }^{[5]}$

Here, we focus on the significant challenge of $\mathrm{CO}_{2}$ capture and highlight recent advances in materials and emerging concepts. The emphasis is on designed materials in which a molecular level of control can be achieved as a means of tailoring their performance in separating relevant gas mixtures. In this regard, particular attention is directed towards the latest developments in $\mathrm{CO}_{2}$ separations using microcrystalline porous solids or metal-organic frameworks. For more in-depth discussions on materials for $\mathrm{CO}_{2}$ separations, the reader is directed to a number of excellent authoritative reviews in the field. ${ }^{[13-21]}$ We also seek to provide some criteria, measurement parameters and performance standards in which materials developed in the laboratory can be

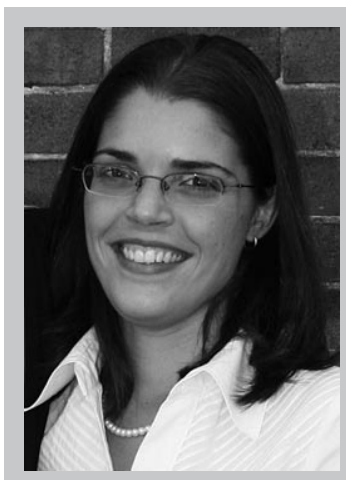

Deanna M. D'Alessandro received her PhD in Chemistry from James Cook University (Australia) in 2006 for which she received the RACI Cornforth Medal and a 2007 IUPAC Prize for Young Chemists. She held a postdoctoral position with Prof. Long at Berkeley (2007-2009) and was a Dow Chemical Company Fellow of the American-Australian Association and an 1851 Royal Commission Fellow. In 2010 she will commence a University of Sydney Research Fellowship focusing on energy-related applications of microporous materials.

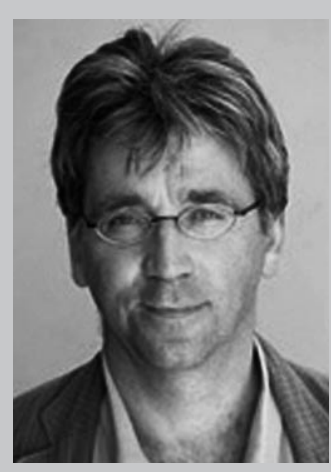

Berend Smit received his PhD in Chemistry from Utrecht University. From 1988 to 1997, he worked as a researcher at Shell Research. In 1997, he returned to academia as Professor of Chemistry at the University of Amsterdam. In 2005, he was elected as director of CECAM in Lyon, France. Since 2007, he has been Professor of Chemical Engineering and Chemistry at the University of California, Berkeley. Since 2009 he has been director of the US Department of Energy EFRC focusing on carbon capture. His research interests include the development and application of advanced molecular simulation techniques. 
evaluated and readily compared so as to assess their performance and guide further experimental efforts. Analysis according to benchmark criteria will permit the most promising materials to be determined in a timely fashion, thereby accelerating their deployment at the industrial scale.

\subsection{Key Challenges for $\mathrm{CO}_{2}$ Capture}

Two points must first be made with regards to capture materials and potential capture technologies, given the sheer magnitude of global $\mathrm{CO}_{2}$ emissions. ${ }^{[8]}$ First, any chemical employed to capture $\mathrm{CO}_{2}$ will rapidly exhaust its global supplies if it is used in a once-through manner; and second, any chemical produced from $\mathrm{CO}_{2}$ as a reactant will rapidly saturate global markets for that chemical. These considerations underscore the necessity that capture materials must be regenerable. In this case, the energy input for regeneration is one of the key factors in determining the efficiency and cost.

Three $\mathrm{CO}_{2}$ separation issues are considered to hold the greatest promise for reducing $\mathrm{CO}_{2}$ emissions, namely 1) separation from power plant flue streams, 2) separation from sour natural gas wells, and 3) separation from fuel gas (i.e., syngas). Each application involves different gas separations which impose distinct requirements and constraints for

Table 1: Benchmark parameters showing typical compositions of gases (by weight) in postcombustion and precombustion processes, and the kinetic diameter of the gas molecules. ${ }^{[22]}$

\begin{tabular}{llll}
\hline & Postcombustion & Precombustion $^{[a]}$ & $\begin{array}{l}\text { Kinetic } \\
\text { diameter }[\AA]\end{array}$ \\
\hline Composition & & & \\
$\mathrm{CO}_{2}$ & $15-16 \%$ & $35.5 \%$ & 3.30 \\
$\mathrm{H}_{2} \mathrm{O}$ & $5-7 \%$ & $0.2 \%$ & 2.65 \\
$\mathrm{H}_{2}$ & & $61.5 \%$ & 2.89 \\
$\mathrm{O}_{2}$ & $3-4 \%$ & & 3.45 \\
$\mathrm{CO}$ & $20 \mathrm{ppm}$ & $1.1 \%$ & 3.75 \\
$\mathrm{~N}_{2}$ & $70-75 \%$ & $0.25 \%$ & 3.64 \\
$\mathrm{SO}_{x}$ & $<800 \mathrm{ppm}$ & & \\
$\mathrm{NO}_{x}$ & $500 \mathrm{ppm}$ & & \\
$\mathrm{H}_{2} \mathrm{~S}$ & & $1.1 \%$ & \\
Conditions & & & \\
Temperature & $50-75^{\circ} \mathrm{C}$ & $40{ }^{\circ} \mathrm{C}$ & \\
Pressure & 1 bar & 30 bar & \\
\hline
\end{tabular}

[a] After water-gas shift reaction.

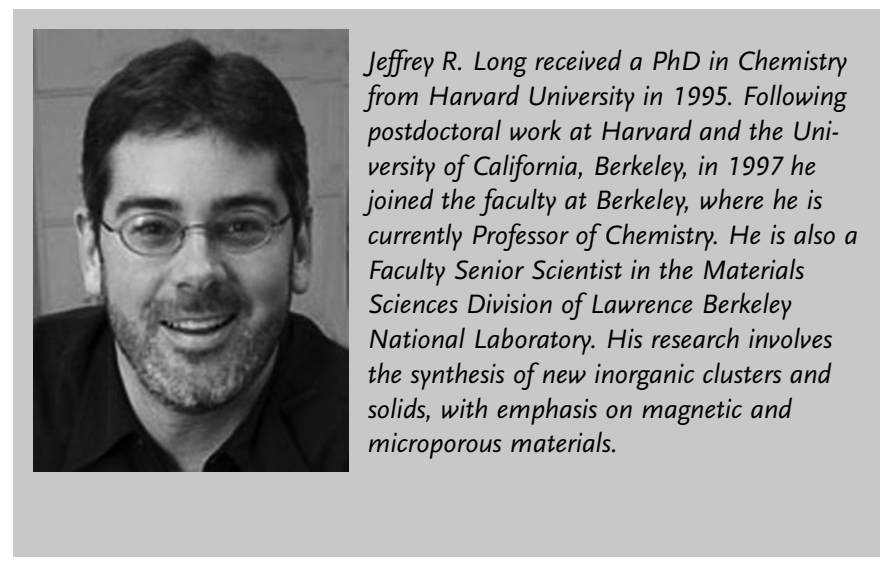

materials. Table 1 summarizes the typical gas compositions and properties relevant to postcombustion and precombustion processes, which should provide some benchmark criteria for experimentalists studying gas separation.

For postcombustion capture from flue gas, a major obstacle is the low pressure of the flue gas (ca. $1 \mathrm{~atm}$ ). The $\mathrm{CO}_{2}$ concentration is low (ca. $15 \%$ ), and capture requires separation from a high volume stream of flue gas containing other component gases, predominantly $\mathrm{N}_{2}$ (see Table 1 ). Although current postcombustion capture technology is suitable for the retrofitting of existing plants, the energy penalty for a coal-fired power station using traditional aqueous monoethanolamine (MEA) for capture has been estimated as 25 to $40 \%$. $^{[6,8,9]}$

Natural gas reserves (mainly $\mathrm{CH}_{4}$ ) are typically contaminated with over $40 \% \mathrm{CO}_{2}$ and $\mathrm{N}_{2}$, and the utilization of such gas fields is only acceptable if this additional $\mathrm{CO}_{2}$ is separated and sequestered at the source of production. This application requires an efficient separation of $\mathrm{CO}_{2}$ from the natural gas components at high pressures. $\mathrm{CO}_{2}$ separation from fuel gas (e.g., output from gasification, water-gas shift reactors) also occurs under high pressure conditions at high temperatures $\left(250-450^{\circ} \mathrm{C}\right)$, with the relevant precombustion separation being $\mathrm{CO}_{2} / \mathrm{H}_{2}$.

The key challenge for gas separations materials is that the differences in properties between the gases that have to be separated are relatively small, as is evident from the kinetic diameters provided in Table 1 (note that the kinetic diameter is a reflection of the smallest effective dimension of a given molecule). However, differences do exist in the electronic properties (i.e., quadrupolar moment and polarization) of the gases: $\mathrm{CO}_{2}$ has a large quadrupole moment $\left(13.4 \times 10^{-40} \mathrm{Cm}^{2}\right.$ vs. $4.7 \times 10^{-40} \mathrm{Cm}^{2}$ for $\mathrm{N}_{2}, \mathrm{CH}_{4}$ is non-polar), and $\mathrm{CH}_{4}$ adsorbs preferentially over $\mathrm{N}_{2}$ due to its higher polarizability $(26.3 \times$ $10^{-25} \mathrm{~cm}^{3}$ for $\mathrm{CO}_{2}$ vs. $17.6 \times 10^{-25} \mathrm{~cm}^{3}$ for $\mathrm{N}_{2}$ and $26.0 \times$ $10^{-25} \mathrm{~cm}^{3}$ for $\left.\mathrm{CH}_{4}\right)$. ${ }^{[23]}$

Novel concepts for capture therefore require a molecular level of control that can take advantage of differences in the chemical reactivity of the gas molecules. A further challenge is that the selectivity of a separation process is determined by a combination of adsorption and diffusion selectivity, which are coupled in most materials. For example, the introduction of a functional group that specifically binds one species, and improves on the adsorption selectivity, will simultaneously decrease the diffusion of these molecules. This inverse relationship between the adsorption and diffusion selectivity has recently been investigated extensively by Krishna ${ }^{[24]}$ in a broad range of meso- and microporous materials including zeolites, carbon nanotubes, carbon molecular sieves, and metal-organic frameworks. The need therefore exists to design materials in which one can independently tune the diffusion and adsorption selectivity at the molecular level. The capture of $\mathrm{CO}_{2}$ from ambient air has also been cited as a strategy to reduce atmospheric $\mathrm{CO}_{2}$ levels, particularly with respect to small and mobile emission sources (e.g., aircraft and home furnaces). ${ }^{[25]}$ Clearly, the low concentration of $\mathrm{CO}_{2}$ in air $(0.04 \%)$ presents a significantly higher thermodynamic barrier to capture compared with postcombustion methods, while the expense of moving large volumes of air through an 
absorbing material presents a further challenge. Indeed, the detailed costs of such approaches are the subject of much debate, and are outside the scope of this article. The uncertainties in future scenarios of desired $\mathrm{CO}_{2}$ levels in the atmosphere, however, emphasize the importance of exploring, from a research point of view, the synergies between direct air capture and capture from flue gasses.

\section{Conventional Chemical Absorption}

Postcombustion "wet-scrubbing" $\mathrm{CO}_{2}$ capture technologies have been employed industrially for over 50 years and are based predominantly on the industrially important primary alkanolamine MEA. ${ }^{[6]}$ The process involves the passage of an aqueous amine solution (typically 25-30 wt. \% ) down the top of an absorption tower, while a gaseous stream of flue gas containing $\mathrm{CO}_{2}$ is introduced at bottom. A blower is required to pump the gas through the absorber. At a temperature of approximately $40^{\circ} \mathrm{C}$, the reaction of $\mathrm{CO}_{2}$ with the amine occurs through a zwitterion mechanism to form carbamates, a reaction that has been extensively studied (Scheme 1a). ${ }^{[26]}$ The liquid amine $\mathrm{CO}_{2}$-rich solvent passes

a)

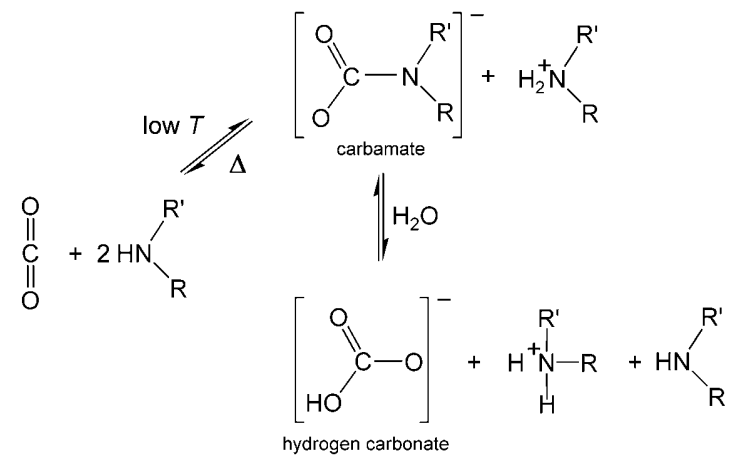

b)

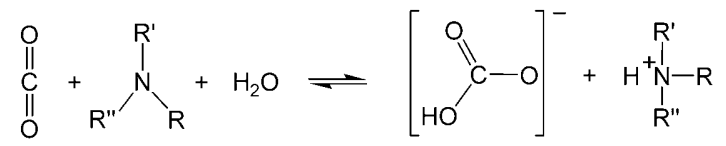

Scheme 1. General reaction schemes for the chemical absorption of $\mathrm{CO}_{2}$ by a) primary or secondary and b) tertiary amine-containing solvents.

from the absorber column to a stripping tower where the mixture is heated with steam to liberate the $\mathrm{CO}_{2}$. The regeneration of the chemical solvent is carried out at elevated temperatures $\left(100-140^{\circ} \mathrm{C}\right)$ and pressures not much higher than atmospheric pressure. The high heat of formation associated with carbamate production leads to a considerable energy penalty for regeneration of the solvent. Following regeneration, the amine solution is cycled back to the absorption tower for additional $\mathrm{CO}_{2}$ absorption.

Whilst postcombustion methods are advantageous in that the technology is commercially mature and can be easily retrofitted into existing power plants, they suffer a number of drawbacks. These include the considerable energy requirements for solvent regeneration and the necessary use of inhibitors to control corrosion and oxidative degradation due to residual oxygen in the flue stream. The sensitivity of the solvents to chemical degradation from other by-products in the flue gas streams, such as $\mathrm{SO}_{x}$ and $\mathrm{NO}_{x}$, also lead to reduced efficiencies and increased costs for electricity production. Improved strategies for postcombustion capture include the use of liquids with lower heats of adsorption, increasing the concentration of the adsorbent molecules and improving the mass transfer and reaction kinetics. The use of other amine-based molecules with lower regeneration temperatures have thus been considered for chemical absorption. Secondary amines such as diethanolamine (DEA) possess a lower heat of reaction compared with primary amines: the lower stability of the carbamate formed upon $\mathrm{CO}_{2}$ absorption gives rise to a more economical regeneration step for the secondary amines.

As shown in Scheme $1 \mathrm{a}$, the $\mathrm{CO}_{2}$ loading capacity for primary and secondary amines lies in the range $0.5-1 \mathrm{~mol}$ of $\mathrm{CO}_{2}$ per mol of amine, since a fraction of the carbamate species is hydrolyzed to form hydrogen carbonates. The reaction of $\mathrm{CO}_{2}$ with tertiary amines such as $\mathrm{N}$-methyldiethanolamine (MDEA) occurs with a higher loading capacity of $1 \mathrm{~mol}$ of $\mathrm{CO}_{2}$ per mol of amine, albeit with a relatively lower reactivity towards $\mathrm{CO}_{2}$ compared with the primary amines. The carbamation reaction (Scheme $1 \mathrm{a}$ ) cannot proceed for tertiary amines, leading instead to a base-catalyzed hydration of $\mathrm{CO}_{2}$ to form hydrogen carbonate (Scheme 1b). ${ }^{[26]}$ MDEA is commonly employed for natural gas treatment and exhibits lower solvent degradation rates in addition to a low energy penalty for regeneration of the solvent in the stripper. In practice, the addition of small amounts of primary and secondary amines enhances the $\mathrm{CO}_{2}$ absorption rates for tertiary amines.

Specialty amines such as hindered amines have been formulated to overcome some of the limitations of the conventional primary, secondary, and tertiary amines. A number of reports on the thermodynamic capacity and absorption/desorption rates of $\mathrm{CO}_{2}$-amine reactions have identified the steric hindrance and basicity of the amine as the major factors controlling the efficiency of $\mathrm{CO}_{2}$ capture reactions. ${ }^{[26-30]}$ Sterically hindered amines such as 2-amino-2methyl-1-propanol (AMP) which contain bulkier substituents have been identified as the most promising absorption solvents due to the lower stability of their carbamates (carbamate stability constant: AMP, $0.1<$ DEA, $2.0<$ MEA, 12.5 at $303 \mathrm{~K}){ }^{[26]}$ The sterically hindered amines allow $\mathrm{CO}_{2}$ loadings well in excess of $0.5 \mathrm{~mol}$ equivalents to be attained, with higher regeneration rates (and therefore lower regeneration costs) compared with the conventional alkanolamines (e.g., the $\mathrm{CO}_{2}$ regeneration rate ratio for AMP/MEA is $1.83^{[28]}$ ). Differences in the absorption rate within the class of hindered amines have also been observed: $:^{[26]}$ for example, 2-piperidineethanol exhibits superior performance compared with AMP and the conventional alkanolamines due to its lower carbamate stability and higher rate constant for reaction with $\mathrm{CO}_{2}$.

Inorganic solvents such as aqueous potassium and sodium carbonate as well as aqueous ammonia solutions have also been considered for chemical absorption. The chilled-ammo- 
nia process for $\mathrm{CO}_{2}$ capture involves the reversible formation of ammonium hydrogen carbonate, with the forward reaction to capture $\mathrm{CO}_{2}$ as solid $\mathrm{NH}_{4} \mathrm{HCO}_{3}$ occurring at temperatures below $20^{\circ} \mathrm{C}{ }^{[8,31]}$ In the regeneration stage, the $\mathrm{CO}_{2}$-rich aqueous ammonium carbonate solution is heated to approximately $80^{\circ} \mathrm{C}$ to redissolve the solids. The use of potassium carbonate (20-40 wt. \% $\mathrm{K}_{2} \mathrm{CO}_{3}$ in water) is also currently nearing the pilot stage for both natural gas and coal-fired power plants, and is already a mature technology in the oil and gas industry for $\mathrm{CO}_{2}$ capture from pressurized well gases. ${ }^{[8]}$ As a final point, $\mathrm{CO}_{2}$ capture from ambient air using chemical absorption in aqueous alkali hydroxide solutions has also been proposed. ${ }^{[25]}$ Despite the strongly absorbing nature of the solutions, the large energy demands of the regeneration step present a comparable problem to that involved in postcombustion $\mathrm{CO}_{2}$ capture from power plants.

\section{Emerging Methods for $\mathrm{CO}_{2}$ Capture}

While the retrofitting of existing power plants using postcombustion capture methods presents the closest marketable technology, two major alternatives to postcombustion processes exist. ${ }^{[12,32]}$ The emerging technologies of precom-

which involve three stages. Initially, a fuel (natural gas in this case) is reacted at high pressure and temperature to form a synthesis gas (syngas) containing $\mathrm{CO}, \mathrm{CO}_{2}$, and $\mathrm{H}_{2}$ [Eq. (1)]. The second stage involves $\mathrm{CO}$ conversion using a water-gas shift reactor in which the $\mathrm{CO}_{2}$ and hydrogen are separated prior to combustion [Eq. (2)].

$$
\begin{aligned}
& \mathrm{H}_{2} \mathrm{O}+\mathrm{CH}_{4} \rightarrow 3 \mathrm{H}_{2}+\mathrm{CO} \\
& \mathrm{H}_{2} \mathrm{O}+\mathrm{CO} \rightarrow \mathrm{H}_{2}+\mathrm{CO}_{2}
\end{aligned}
$$

The significant advantage of precombustion capture is that the higher component concentrations and elevated pressures reduce the energy capture penalty of the process to $10-16 \%$, roughly half that for postcombustion $\mathrm{CO}_{2}$ capture. ${ }^{[33]}$ Although the initial fuel conversion steps are more elaborate and costly than in postcombustion systems, the high concentrations of $\mathrm{CO}_{2}$ produced by the shift reactor (typically 15 to $60 \%$ by volume on a dry basis) and the high pressures often encountered in these applications are more favorable for $\mathrm{CO}_{2}$ separation. A further advantage is that precombustion technology generates a hydrogen-rich fuel, which can be used as a chemical feedstock, in a fuel cell for power generation, or in the development of a hydrogen economy. While no commercial IGCC plants with CCS are yet in operation, the largest proposed projects include the recently re-instated $275 \mathrm{MW}$ FutureGen plant in the U.S. and China's $250 \mathrm{MW}$ GreenGen project which is scheduled to commence operation in 2011. ${ }^{[9]}$

In contrast to post- and precombustion methods, oxyfuel combustion takes place in a pressurized $\mathrm{CO}_{2}$-rich recirculating stream in which nitrogen is completely excluded from the combustion process through a preliminary air separation step (Figure 2). ${ }^{[12]}$ Suitable fuels include coal, natural gas, light to medium hydrocarbons or syngas (which could be derived from coal). The product of combustion is a concentrated stream of $\mathrm{CO}_{2}$ (in high, sequestration ready concentrations of 80 $98 \%$ ), which is circulated back into the system. The water product is removed from the flue gas by condensation.

Oxyfuel technology forms the basis for "zero emission cycle" plants which are considered more promising for new installations compared with postcombustion

bustion capture and oxyfuel processes (Figure 2) are projected to attain higher efficiencies for $\mathrm{CO}_{2}$ separation and capture which will compensate for their extensive capital investments in the longer term. ${ }^{[7]}$

Precombustion methods are employed in natural gas plants where $\mathrm{CO}_{2}$ capture occurs at high partial pressures. ${ }^{[9,12,33]}$ The precombustion process for converting a methane rich fuel into hydrogen, for example, has given rise to Integrated Gasification Combined Cycle (IGCC) plants
$\mathrm{CO}_{2}$ capture; however, the process requires significant redesign of the turbines, such that the retrofitting of existing plants is not considered economical. The world's first pilot plant for the capture of carbon dioxide using Oxyfuel technology was inaugurated in September 2008 by the European energy company Vattenfall, at Schwarze Pumpe in Germany. ${ }^{[34]}$ One shortcoming of the process is the significant energy demands of the air separation unit, however, this cost should be mitigated by the elimination of the need for $\mathrm{CO}_{2}$ capture. By 
reducing the volume of inert gas (i.e., $\mathrm{N}_{2}$ ) in the furnace, the thermal efficiency of the boiler unit is also increased. Since the separation of interest in this case is air separation $\left(\mathrm{O}_{2}\right.$ from mainly $\mathrm{N}_{2}$ ), reducing the cost of oxygen generation is key. As an alternative to cryogenic air separation, oxygenselective membranes offer a promising new technology in this regard. ${ }^{[35]}$

\section{New Materials for $\mathrm{CO}_{2}$ Capture}

A diverse range of promising new materials exist for $\mathrm{CO}_{2}$ capture from postcombustion, precombustion, and oxyfuel processes (Figure 3). Significant research efforts have been directed, in particular, towards overcoming the energy

polyethylene glycol) and Rectisol (methanol chilled to $-40^{\circ} \mathrm{C}$ ), for example, have been used industrially for 40 years for natural gas sweetening and the treatment of synthesis gas. The advantage in this case is the lower heat consumption in the solvent regeneration step, as the stripping process can be driven by heat or a pressure reduction (i.e., "flash distillation"). ${ }^{[36]}$ Physical solvents are suitable for $\mathrm{CO}_{2}$ capture from high pressure streams such as those relevant for precombustion capture in IGCC plants.

Ionic liquids constitute another class of physical solvents which are also known to be selective for $\mathrm{CO}_{2}$ absorption. ${ }^{[20,37]}$ These comprise combinations of large organic cations and smaller inorganic anions and are typically viscous liquids near room temperature. In addition to their extremely low vapor pressures, they are non-flammable, environmentally benign, and can exhibit exceptional thermal stability. The mechanism for capture is often based on physisorption, and involves weak association between the ionic liquid and $\mathrm{CO}_{2}$ molecules (rather than chemical bonds), with heats of adsorption of around $-11 \mathrm{~kJ} \mathrm{~mol}^{-1}$. $^{[38,39]}$ In view of this low heat of reaction, the obvious benefit for $\mathrm{CO}_{2}$ capture is the minimal energy required for solvent regeneration. The capacity is directly proportional to the partial pressure of $\mathrm{CO}_{2}$ and improves at pressures above 1-2 bar. For this reason, ionic liquids were initially proposed for precombustion applications. It should be noted that some ionic liquids react with $\mathrm{CO}_{2}$ in a chemisorption mechanism. An additional benefit is that ionic liquids can simultaneously serve to remove $\mathrm{CO}_{2}$ and $\mathrm{SO}_{2}$ (" $\mathrm{SO}_{2}$ polishing"), since the $\mathrm{SO}_{2}$ solubility is 8-25 times greater than that of $\mathrm{CO}_{2}$ at the same partial pressure. ${ }^{[40]}$ This may not necessarily be advantageous, however, as an additional step to separate $\mathrm{CO}_{2}$ from $\mathrm{SO}_{2}$ will be required.

Figure 3. Materials for $\mathrm{CO}_{2}$ capture in the context of postcombustion, precombustion, and oxyfuel processes.

intensive solvent regeneration step and chemical degradation issues which are characteristic of conventional solvent absorbents in postcombustion flue gas separations. Examples of new materials include physical absorbents, adsorption on solids using pressure and/or temperature swing adsorption processes, membranes, cryogenic distillation, gas hydrate formation, and chemical-looping combustion using metal oxides, amongst others. ${ }^{[36]}$

\subsection{Physical Absorbents}

A promising alternative to chemical absorption using solvents such as MEA is the use of physical solvents in which the solvent selectively binds $\mathrm{CO}_{2}$ at high partial pressures and low temperatures (in accordance with Henry's Law). Physical absorbents such as Selexol (a mix of dimethylethers of
While the viscosity of ionic liquids minimizes solvent loss from the gas stream, this attribute also limits mass transfers, and they often suffer from low rates of absorption. To surmount these shortcomings and increase the capacity of simple ionic liquids, "task specific ionic liquids" ${ }^{[41]}$ have been developed. The introduction of functional groups such as amines into TSILs, have allowed higher rates of adsorption to be achieved at pressures relevant to flue streams (ca. 1 bar). A number of reports have also demonstrated extremely high $\mathrm{CO}_{2} / \mathrm{N}_{2}$ selectivities in polymerized ionic liquids, which exhibit enhanced $\mathrm{CO}_{2}$ solubilities relative to the monomeric ionic liquid itself. ${ }^{[42]}$ These solid materials also show exceptional promise as facilitated transport ionic liquid membranes. ${ }^{[43]}$ 


\subsection{Adsorption Materials}

Solid physical adsorbents (in packed or fluidized adsorbent beds) possess significant advantages for energy efficiency compared with chemical and physical absorption approaches. In the case of adsorbents, however, there may be some practical difficulties in achieving the same heat exchange efficiency in the cycle between the hot and cold sections of the capture process. Whereas $\mathrm{CO}_{2}$ molecules dissolve into the bulk of the material in absorption, $\mathrm{CO}_{2}$ adsorption involves either physisorption (van der Waals) or chemisorption (covalent bonding) interactions between the gas molecules and the surface of a material. The $\mathrm{CO}_{2}$-laden solid is purified in stages using pressure, vacuum, or temperature swing adsorption cycles to remove and concentrate the $\mathrm{CO}_{2}$. Several authoritative review articles have discussed characteristics and examples of physical adsorbents, ${ }^{[12-14,20,21,44,45]}$ so rather than being exhaustive, we will focus on the latest and most promising developments in the field during the past few years.

A key concern for physical adsorbents is balancing a strong affinity for removing an undesired component from a gas mixture with the energy consumption required for their regeneration. In addition to the adsorption capacity, the selectivity is a principal property relevant to adsorptive gas separation. While both factors are dependent on the operational temperature and pressure, as well as the nature of the adsorbent and the gas adsorbate, the factors which influence selectivity are more complicated. Possible mechanisms of adsorptive separation include: 1) the molecular sieving effect, which is based upon size/shape exclusion of certain components of a gas mixture; 2) the thermodynamic equilibrium effect, due to preferential adsorbate-surface or adsorbate packing interactions; and 3) the kinetic effect, due to differences in the diffusion rates of different components of a gas mixture. ${ }^{[16]}$

A variety of solid physical adsorbents have been considered for $\mathrm{CO}_{2}$ capture including microporous and mesoporous materials (carbon-based sorbents such as activated carbon and carbon molecular sieves, zeolites, and chemically modified mesoporous materials), metal oxides, and hydrotalcitelike compounds, amongst others. ${ }^{[13]}$

Metal oxides (such as $\mathrm{CaO}$ and $\mathrm{MgO}$ ) are promising capture materials given their ability to retain high adsorption capacities at temperatures above $300^{\circ} \mathrm{C} .^{[13,46]}$ The operation of the materials can be defined by a carbonation-calcination cycle: the carbonation reaction of $\mathrm{CO}_{2}$ with solid $\mathrm{CaO}$ at 600 $650^{\circ} \mathrm{C}$ precipitates calcium carbonate $\left(\mathrm{CaCO}_{3}\right)$, while the reverse calcination reaction regenerates the oxide at 800 $850^{\circ} \mathrm{C}$. On the downside, adsorbent degradation has been observed after several cycles. Improved oxide materials containing lithium, such as $\mathrm{Li}_{2} \mathrm{ZrO}_{3}$ and $\mathrm{Li}_{4} \mathrm{SiO}_{4}$ have recently attracted attention for their high $\mathrm{CO}_{2}$ adsorption capacities. ${ }^{[4]}$

The class of anionic and basic clays known as hydrotalcites and their derivatives have also been shown to be suitable as $\mathrm{CO}_{2}$ adsorbents for precombustion processes at temperatures as high as $400^{\circ} \mathrm{C} .^{[13,48]}$ These compounds belong to a family of layered double hydroxide solids with the general stoichiometry $\mathrm{M}^{2+}{ }_{1-x} \mathrm{M}^{3+}{ }_{x}(\mathrm{OH})_{2} \mathrm{~A}^{m-}{ }_{x / m} \cdot y \mathrm{H}_{2} \mathrm{O}$ where the divalent ion is typically $\mathrm{Mg}^{2+}$, the trivalent ion is typically $\mathrm{Al}^{3+}$, and the anion (A) is $\mathrm{Cl}^{-}, \mathrm{NO}_{3}{ }^{-}$or $\mathrm{CO}_{3}{ }^{2-}$. The majority of studies have focused on the most inexpensive and common naturally occurring form of hydrotalcites, $\mathrm{Mg}-\mathrm{Al}-\mathrm{CO}_{3}$, although recent work has demonstrated that the substituted hydrotalcites such as those containing $\mathrm{Ga}^{3+}$ substituted for some fraction of the $\mathrm{Al}^{3+}$ exhibit enhanced $\mathrm{CO}_{2}$ adsorption properties. ${ }^{[49]}$

The "Dry Carbonate Process" is currently in the experimental stages of development and is nearing implementation in postcombustion coal- and natural-gas pilot plants. ${ }^{[50]}$ Here, flue gas mixes with a solid dry powdered carbonate sorbent (e.g., $\mathrm{Na}_{2} \mathrm{CO}_{3}$ or $\mathrm{K}_{2} \mathrm{CO}_{3}$ ) in a fluidized bed ${ }^{[8]}$ (in the presence of water) to form the corresponding hydrogen carbonate salt $\left(\mathrm{NaHCO}_{3}\right.$ or $\left.\mathrm{KHCO}_{3}\right)$. The regenerative decarbonation reaction can be achieved at a relatively low temperature of ca. $120^{\circ} \mathrm{C}$.

\subsubsection{Microporous and Mesoporous Materials}

Zeolites are amongst the most widely reported physical adsorbents for $\mathrm{CO}_{2}$ capture in the patent and journal literature. ${ }^{[13]}$ They constitute the primary adsorption material for commercial hydrogen production (involving $\mathrm{H}_{2} / \mathrm{CO}_{2}$ separation) using pressure swing adsorption, with the most popular of these based on zeolite $13 \mathrm{X}^{[51]}$ Zeolites are typically employed at elevated pressures (above 2 bar), and their adsorption capacity has been shown to be greatly reduced by the presence of moisture in the gas, thereby necessitating very high regeneration temperatures (often in excess of $\left.300^{\circ} \mathrm{C}\right) .^{[44,52]}$ These additional recovery costs for their regeneration pose a significant disadvantage.

Recently, attention has turned to experimental ${ }^{[44]}$ and computational ${ }^{[53]}$ screening studies to assess $\mathrm{CO}_{2}$ removal from low pressure flue gas using naturally occurring zeolites, such as $\mathrm{X}$ and $\mathrm{Y}$ Faujasite systems, ${ }^{[33]}$ as well as synthetic zeolites including 5A and $13 \mathrm{X}^{[44]}$ Experimental studies on several synthetic zeolites have shown that the most promising candidates for capture of $\mathrm{CO}_{2}$ from a simulated flue gas mixture (consisting of $\mathrm{CO}_{2}$ and $\mathrm{N}_{2}$ ) are characterized by a near linear $\mathrm{CO}_{2}$ adsorption isotherm. However, a trade-off exists here since a linear isotherm is indicative of weak adsorbent-adsorbate interactions, which is not compatible with a high $\mathrm{CO}_{2} / \mathrm{N}_{2}$ selectivity. The adsorption can be enhanced by a low $\mathrm{SiO}_{2} / \mathrm{Al}_{2} \mathrm{O}_{3}$ ratio and the presence of cations in the zeolite structure which exhibit strong electrostatic interactions with $\mathrm{CO}_{2}{ }^{[44]}$ While these potential adsorbents were shown to be adequate for pressure swing adsorption applications, their regeneration required significant energy input.

An advantage of porous solid materials is the ability to modify their properties by impregnating or tethering active groups such as alkyl-amines onto their internal surfaces. This strategy has often been exploited to improve the gas sorption properties of porous materials for low pressure capture applications, such as those relevant in flue streams and for capture from ambient air. In this regard, numerous aminemodified silica materials have been prepared. ${ }^{[13,54]}$ The surface modification with primary amines facilitates the adsorption of $\mathrm{CO}_{2}$ through the formation of carbamate species, reminiscent of the amine- $\mathrm{CO}_{2}$ chemistry in conventional liquid phase scrubbing (see Scheme 1). The stripping of $\mathrm{CO}_{2}$ can be 
achieved at lower temperatures than those required for the regeneration of amine solvents (typically $>100^{\circ} \mathrm{C}$ ), thus decreasing the energy requirements of the process. ${ }^{[5,56]}$ The impregnation of polyethylenimine into periodic MCM-41 mesoporous molecular sieves has also been shown to lead to a significant enhancement (24-fold) in the $\mathrm{CO}_{2}$ absorption capacity of the solid support using a pressure swing adsorption approach. ${ }^{[13,57]}$ Increased absorption capacities were also observed in a series of amines immobilized in supports such as poly(methyl methacrylate). ${ }^{[5]}$ However, these materials impregnated with physisorbed amines often suffer from a lack of stability over repeated cycles.

To overcome these limitations, alkylamines have been covalently tethered to the surface of mesoporous supports in an attempt to increase their stability. For example, aziridine polymerization at the surface of mesoporous silica was used to generate a hyperbranched material which was shown to exhibit reversible $\mathrm{CO}_{2}$ binding (with a capacity of $2 \mathrm{mmol}$ $\mathrm{CO}_{2} / \mathrm{g}$ adsorbent) and multi-cycle stability under simulated flue gas conditions using a temperature swing adsorption (TSA) approach. ${ }^{[54]}$ The influence of the amine type and the presence of moisture on $\mathrm{CO}_{2}$ adsorption performance have also been investigated for SBA-15 grafted with monoamino, diamino, and triamino ethoxysilanes. ${ }^{[59]}$ Capacities of 0.52 , 0.87 , and $1.10 \mathrm{mmol} \mathrm{CO}_{2} / \mathrm{g}$ adsorbent, respectively, were obtained. In the presence of a moist $\mathrm{CO}_{2}$ stream, the capacity decreased slightly for the primary amine, but increased by ca. 3 and $10 \%$ for the secondary and tertiary amine grafted materials, respectively.

A significant conclusion from these studies was the dependence of the adsorption performance on the surface density of the amine groups. ${ }^{[44]}$ In considering the adsorption efficiency of the materials, both the rate of adsorption and the adsorption capacity must be optimal. The amine grafting procedure which is employed often involves the addition of an excess of the grafting reagent to the support. However, the amount which is ultimately grafted to the surface may vary over repeat syntheses, and may not result in an optimal amount of grafted amine for the particular $\mathrm{CO}_{2}$ capture process. These considerations highlight the importance of studies on the influence of the quantity of grafting reagent added on the actual amount of amine that is covalently attached to the surface. Only with this data in hand, can the performance of new solid adsorbents for the $\mathrm{CO}_{2}$ capture applications highlighted here be critically assessed.

\subsubsection{Carbonaceous Adsorbents}

Adsorption studies on activated carbon, charcoal, and virgin coal have focused on high pressure $\mathrm{CO}_{2}$ capture applications given that the adsorption capacities scale with pressure. ${ }^{[13,60]}$ While the surface properties of the adsorbents can vary widely, the materials are advantageous in that they are inexpensive relative to other solid adsorbents (such as zeolite 13X), and are insensitive to moisture.

The majority of studies on carbon-based sorbents are motivated by the significant industrial potential of enhanced oil recovery schemes, which involve the $\mathrm{CO}_{2}$-driven displacement of valuable oil from underground reserves. ${ }^{[7]}$ Although these processes are already operational worldwide, the use of $\mathrm{CO}_{2}$ (rather than the conventional technique requiring vast quantities of water) has been cited as a more environmentally feasible and attractive alternative. ${ }^{[20]}$

Few studies on carbonaceous adsorbents have investigated their feasibility for low pressure flue gas applications using vacuum or temperature swing regeneration approaches. In a recent study, activated carbon and charcoal were shown to exhibit moderate adsorption selectivity for $\mathrm{CO}_{2}$ over $\mathrm{N}_{2}$ (defined as the ratio of the pure-component sorption capacities) at low pressures below $1 \mathrm{~atm}$, while increasing the pressure reduced the selectivity. ${ }^{[20]}$ In general, the selectivity and capacity of carbonaceous adsorbents is too low for postcombustion applications; however, activated carbons are attractive for precombustion $\mathrm{CO}_{2}$ capture.

A technique gaining increasing interest for use in $\mathrm{CO}_{2}$ capture with carbon-based sorbents is electrical swing adsorption. Examples include conductive monolithic mesoporous carbon adsorbents, which rapidly adsorb and desorb $\mathrm{CO}_{2}$ with the application and removal of electric charge. ${ }^{[61]}$

\subsubsection{Organic Solids}

Non-porous self-assembled p-tert-butylcalix[4]arene organic solids have also been considered for $\mathrm{CO}_{2}$ capture. ${ }^{[62,63]}$ The structure is characterized by cone-shaped calixarene molecules that are stabilized by intramolecular hydrogen bonds, as well as the presence of hydrophobic nanodimensional channels. Upon exposure of the solid to a high pressure of $\mathrm{CO}_{2}(35 \mathrm{~atm})$ at room temperature, the network undergoes a gas driven single-crystal-to-single-crystal phase transformation from the "guest-free" thermodynamic form to the kinetic form over ca. $2 \mathrm{~h} .{ }^{[63]} \mathrm{A} \mathrm{CO}_{2}$ capacity of $6.9 \mathrm{wt} \%$ and enthalpy of adsorption of $-16 \mathrm{~kJ} \mathrm{~mol}^{-1}$ was observed, while exposure of the solid to $20 \mathrm{~atm}$ of $\mathrm{H}_{2}$ gas did not result in any detectable adsorption. ${ }^{[62]}$ The materials may be applicable for highpressure $\mathrm{CO}_{2} / \mathrm{H}_{2}$ syngas separations.

Recent work has demonstrated the potential of covalent organic frameworks (COFs) for $\mathrm{CO}_{2}$ capture. ${ }^{[64]}$ These are crystalline microporous materials similar to the metalorganic frameworks discussed below, but with frameworks built up of only lightweight organic components. COF-102 $\left(\mathrm{C}_{25} \mathrm{H}_{24} \mathrm{~B}_{4} \mathrm{O}_{8}\right)$ is comprised of tetra(4-(dihydroxy)borylphenyl)methane units and exhibits the highest $\mathrm{CO}_{2}$ uptake, to date, in this class $\left(27 \mathrm{mmolg}^{-1}\right.$ at $55 \mathrm{bar}$ and $\left.298 \mathrm{~K}\right){ }^{[64]}$ Molecular simulations have corroborated the experimental findings, predicting exceptionally high uptakes in these materials. $^{[65,66]}$

\subsubsection{Metal-Organic Frameworks}

The past 20 years have seen remarkable progress in the design, synthesis, and characterization of metal-organic frameworks (MOFs) owing to their enormous structural and chemical diversity and their potential applications in gas storage, ion exchange, molecular separation, and heterogeneous catalysis. ${ }^{[67-79]}$ These microporous crystalline solids are composed of organic bridging ligands or "struts" coordinated to metal-based nodes to form a three-dimensional extended 
network with uniform pore diameters typically in the range 3 to $20 \AA .{ }^{[80-85]}$ The nodes generally consist of one or more metal ions (e.g., $\mathrm{Al}^{3+}, \mathrm{Cr}^{3+}, \mathrm{Cu}^{2+}$, or $\mathrm{Zn}^{2+}$ ) to which the organic bridging ligands coordinate through a specific functional group (e.g., carboxylate, pyridyl). The intense current research efforts towards industrial applications of MOFs in gas storage, separation, and catalysis is attributed to their unique structural properties, including: robustness, high thermal and chemical stabilities, unprecedented internal surface areas (up to $5000 \mathrm{~m}^{2} \mathrm{~g}^{-1}$ ), high void volumes (55$90 \%$ ), and low densities (from 0.21 to $1.00 \mathrm{~g} \mathrm{~cm}^{-3}$ ), which can be maintained upon evacuation of the guest molecules from the pores. ${ }^{[86]}$ The regular monodisperse nature of the crystalline array of micropores is a key feature that distinguishes these systems from other porous materials (e.g., polymers, mesoporous silicas, carbons, etc.). In addition, the ability to modulate systematically the pore dimensions and surface chemistry within metal-organic frameworks ${ }^{[87]}$ is a feature that was previously largely absent in zeolite materials. Here, we focus on four sub-sets of metal-organic frameworks, namely those which contain open metal sites, interpenetrated frameworks, flexible frameworks, and surface-functionalized frameworks.

The high surface area-to-weight ratio of MOFs is such that they have enhanced capacities for $\mathrm{CO}_{2}$ capture at moderate pressures compared with zeolites. While zeolites possess higher storage capacities at pressures of less than 10 bar, it has been projected that their maximum capacities are limited to one third those of MOFs at pressures greater than 10 bar. $^{[8]}$ The capacities of metal-organic frameworks up to high pressures scale with the amount of active area per unit weight: activated carbon has an active area of 400 $1000 \mathrm{~m}^{2} \mathrm{~g}^{-1}$, zeolites of up to $1500 \mathrm{~m}^{2} \mathrm{~g}^{-1}$, and frameworks of $1500-4500 \mathrm{~m}^{2} \mathrm{~g}^{-1}$. $^{[8]}$

In addition to the adsorption capacity, the selectivity is a principal property relevant to adsorptive gas separation, and is determined by an interplay of factors including the molecular sieving effect, the thermodynamic equilibrium effect, and the kinetic effect. ${ }^{[16]}$ While the mechanism for $\mathrm{CO}_{2}$ capture and separation can often be determined predominantly by one of these factors, it is more often the case that a synergistic combination of effects is operative. Table 2 summarizes the examples of metal-organic frameworks reported to date that have been explored for applications in $\mathrm{CO}_{2} / \mathrm{N}_{2}$ (postcombustion), $\mathrm{CO}_{2} / \mathrm{H}_{2}$ (precombustion) or $\mathrm{CO}_{2} / \mathrm{CH}_{4}$ (natural gas sweetening) separations.

The peak gravimetric adsorption for $\mathrm{CO}_{2}$ has been reported in frameworks with high surface areas and pore diameters of greater than $15 \AA$. The framework $\left[\mathrm{Zn}_{4} \mathrm{O}(\mathrm{btb})_{2}\right]$ (MOF-177, btb ${ }^{3-}=1,3,5$-benzenetribenzoate) with a surface area (SA) of $4500 \mathrm{~m}^{2} \mathrm{~g}^{-1}$ exhibits the highest capacity for $\mathrm{CO}_{2}$, taking up $33.5 \mathrm{mmolg}^{-1}$ at 32 bar. $^{[88]}$ By comparison, the benchmark material zeolite $13 \mathrm{X}$ adsorbs $7.4 \mathrm{mmolg}^{-1}$ at 32 bar (Table 2). ${ }^{[88]}$ High surface area frameworks such as $\left[\mathrm{Cu}_{2}(\mathrm{BPnDC})_{2}(\mathrm{bpy})\right] \quad$ (SNU-6, bpy $=4,4^{\prime}$-bipyridine, $\mathrm{BpnDC}^{2-}=$ benzophenone-4,4'-dicarboxylate, $\quad \mathrm{SA}_{\mathrm{BET}}=$ $2590 \mathrm{~m}^{2} \mathrm{~g}^{-1}$ ) also possess a high $\mathrm{CO}_{2}$ uptake capacity and preferential $\mathrm{CO}_{2}$ adsorption over $\mathrm{CH}_{4}{ }^{[89]}$
Other terephthalate-based materials have been extensively investigated with regard to their $\mathrm{CO}_{2}$ capture properties. For example, room temperature $\mathrm{CO}_{2}$ adsorption has been reported in a series of isoreticular frameworks including $\left[\mathrm{Zn}_{4} \mathrm{O}(\mathrm{bdc})_{3}\right] \quad\left(\mathrm{MOF}-5, \quad \mathrm{bdc}^{2-}=1,4\right.$-benzenedicarboxylate $)$ and $\left[\mathrm{Zn}_{4} \mathrm{O}\left(\mathrm{NH}_{2} \mathrm{bdc}\right)_{3}\right]\left(\mathrm{NH}_{2} \mathrm{bdc}^{2-}=2\right.$-amino-1,4-benzenedicarboxylate). ${ }^{[88]}$ Notably, the isotherms exhibited an interesting S-shaped profile in which the presence of inflection points indicated electrostatic interactions between the $\mathrm{CO}_{2}$ molecules themselves, which dominate as the pressure increases.

Measurements on the adsorption kinetics for $\mathrm{CO}_{2}$ in $\left[\mathrm{Zn}_{4} \mathrm{O}(\mathrm{bdc})_{3}\right]^{[88,90,91]}$ showed that the activation energy for diffusion is directly proportional to the ratio of the kinetic diameter of the diffusing molecule to the pore opening of the structure (as is the case for zeolites). Based on this rationale, frameworks with smaller pores possess a higher barrier to diffusion. $^{[90]}$

A molecular sieving effect can be exploited for the separation of gas mixtures in cases where the pore sizes are sufficiently small, and are in the range of the kinetic diameters of the adsorbates. For example, the frameworks $\left[\mathrm{Zn}_{4} \mathrm{O}(\mathrm{fma})_{3}\right]$ $(\mathrm{fma}=\text { fumarate })^{[92]}$ and $\left[\mathrm{Sc}_{2}(\mathrm{bdc})_{3}\right]^{[93]}$ possess smaller pores than those in the aforementioned structures such as $\left[\mathrm{Zn}_{4} \mathrm{O}\right.$ $(\mathrm{bdc})_{3}$ ] which lie in the range required for industrially important gas separations (Table 1). ${ }^{[92]}$ The slow kinetics associated with diffusion through small pores, however, could be problematic for separation materials which are designed solely on the basis of kinetic size considerations.

In addition to such kinetic size effects, favorable electrostatic interactions between $\mathrm{CO}_{2}$ and the framework also provide enhanced capture, as in the case of $[\mathrm{Al}(\mathrm{OH})(\mathrm{ndc})]$ (ndc ${ }^{2-}=1,4$-napthalenedicarboxylate). ${ }^{[94]}$ Gas uptake measurements revealed that while $\mathrm{CO}_{2}$ (kinetic diameter $3.3 \AA$ ) is excluded from entering the $3.0 \AA$ diameter pores, favorable interactions between the hydroxy groups of the framework protruding toward the $7.7 \AA$ diameter channels give rise to preferential $\mathrm{CO}_{2}$ adsorption over $\mathrm{N}_{2}$ (by a factor of ca. 10).

The selective capture of $\mathrm{CO}_{2}$ from $\mathrm{CO}_{2} / \mathrm{CH}_{4}$ mixtures can be achieved by exploiting the favorable interactions between the framework and the quadrupole moment of $\mathrm{CO}_{2}(13.4 \times$ $10^{-40} \mathrm{Cm}^{2}$, compared with $\mathrm{CH}_{4}$ which is non-polar). For $\left[\mathrm{Zn}_{2}(\mathrm{bpdc})_{2}(\mathrm{dpni})\right] \quad\left(\mathrm{dpni}=N, N^{\prime}\right.$-di(4-pyridyl)-1,4,5,8-naphthalenetetracarboxydiimide, bpdc ${ }^{2-}=$ biphenyl-4,4'-dicarboxylate), ${ }^{[95,96]}$ a $\mathrm{CO}_{2} / \mathrm{CH}_{4}$ selectivity of ca. 30 was calculated using the ideal adsorbed solution theory (IAST). While the majority of adsorption studies have reported selectivities based on single component adsorption isotherms, IAST serves as the benchmark for the simulation and computational analysis of binary mixture adsorption from the experimental isotherms. ${ }^{[97]}$

Zeolitic imidazolate frameworks (ZIFs) constitute a subclass of metal-organic frameworks that can adopt zeolite structure types based on the replacement of: 1) tetrahedral $\mathrm{Si}^{4+}$ and $\mathrm{Al}^{3+}$ ions with tetrahedral transition metal ions such as $\mathrm{Zn}^{2+}$ or $\mathrm{Co}^{2+}$ and 2) bridging $\mathrm{O}^{2-}$ ions with bridging imidazolate-based ligands. A recent extensive review article ${ }^{[98]}$ has highlighted the exceptional selective $\mathrm{CO}_{2}$ capture and storage properties of ZIFs. ${ }^{[99-101]}$ High-throughput synthetic methods have been utilized with great utility to produce 
Table 2: $\mathrm{CO}_{2}$ capture and separation properties of selected metal-organic frameworks categorized as 1) containing open metal sites, 2) interpenetrated, 3) flexible, and 4) functionalized.

\begin{tabular}{|c|c|c|c|c|c|}
\hline Material ${ }^{[a]}$ & Category & $\begin{array}{l}\mathrm{CO}_{2} \text { uptake } \\
\text { (conditions) }^{[\mathrm{b}]}\end{array}$ & $\begin{array}{l}-\Delta H_{\text {ads }} \\
{\left[\mathrm{kJ} \mathrm{mol}{ }^{-1}\right]^{[\mathrm{c}]}}\end{array}$ & $\begin{array}{l}\text { Separation } \\
\text { application, } \\
\text { Selectivity }^{[\mathrm{d}]}\end{array}$ & Ref. \\
\hline$\left[\mathrm{Zn}_{4} \mathrm{O}(\mathrm{btb})_{2}\right](\mathrm{MOF}-177)$ & & $33.5 \mathrm{mmolg}^{-1}$ (298 K, $\left.32 \mathrm{bar}\right)$ & & & {$[88]$} \\
\hline$\left[\mathrm{Zn}_{4} \mathrm{O}(\mathrm{bdc})_{3}\right](\mathrm{MOF}-5)$ & & $2.10 \mathrm{mmolg}^{-1}, 9.24 \mathrm{wt} \%(295 \mathrm{~K}, 1 \mathrm{~atm})$ & & & [88] \\
\hline$\left[\mathrm{Zn}_{4} \mathrm{O}\left(\mathrm{NH}_{2} \mathrm{bdc}\right)_{3}\right]$ & $(4)$ & & & & {$[88]$} \\
\hline$\left[\mathrm{Zn}_{4} \mathrm{O}(\mathrm{fma})_{3}\right]$ & & $\begin{array}{l}69 \text { wt } \% \mathrm{CO}_{2} \text { vs. } 8.6 \text { wt } \% \mathrm{CH}_{4} \\
(300 \mathrm{~K}, 28 \text { bar) }\end{array}$ & 16.1 vs. $12.0 \mathrm{CH}_{4}$ & $\mathrm{CO}_{2} / \mathrm{CH}_{4}$ & {$[92]$} \\
\hline$\left[\mathrm{Sc}_{2}(\mathrm{bdc})_{3}\right]$ & & $\begin{array}{l}0.9 \mathrm{mmolg}^{-1}(235 \mathrm{~K}, 1 \mathrm{bar}), 4.5 \mathrm{mmolg}^{-1} \\
(50 \text { bar) }\end{array}$ & $20-25$ & $\mathrm{CO}_{2} / \mathrm{CH}_{4} ; \mathrm{CO}_{2} / \mathrm{H}_{2}$ & {$[93]$} \\
\hline$\left[\mathrm{Zn}_{2}(\mathrm{bpdc})_{2}(\mathrm{dpni})\right]$ & & & & $\begin{array}{l}\mathrm{CO}_{2} / \mathrm{CH}_{4}, \approx 30^{1 \mathrm{AST}} \\
(296 \mathrm{~K}, 0-18 \text { bar })\end{array}$ & [95-97] \\
\hline$\left[\mathrm{Cu}_{2}(\mathrm{BPnDC})_{2}(\mathrm{bpy})\right](\mathrm{SNU}-6)$ & & $\begin{array}{l}25.8 \mathrm{mmolg}^{-1}, 114 \mathrm{wt} \%(195 \mathrm{~K}, 1 \mathrm{bar}) \\
2.50 \mathrm{mmolg}^{-1}, 11 \mathrm{wt} \% \text { vs. } 0.69 \mathrm{mmolg}^{-1} \text {, } \\
1.11 \mathrm{wt} \% \mathrm{CH}_{4}(273 \mathrm{~K}, 1 \mathrm{~atm})\end{array}$ & & & {$[89]$} \\
\hline$\left[\mathrm{Cu}_{3}(\mathrm{btc})_{2}\right]$ & (1) & $\begin{array}{l}10.9 \mathrm{mmolg}^{-1}(298 \mathrm{~K}, 6 \mathrm{bar}), 12.7 \mathrm{mmol} \mathrm{g}^{-1} \\
(15 \mathrm{bar}) \text { vs. } \approx 4 \mathrm{mmolg}^{-1} \mathrm{CH}_{4}(15 \mathrm{bar}) \\
\text { and } \approx 2 \mathrm{mmolg}^{-1} \mathrm{~N}_{2} \text { (15 bar) }\end{array}$ & $30-35$ & $\mathrm{CO}_{2} / \mathrm{CH}_{4} ; \mathrm{CO}_{2} / \mathrm{N}_{2}$ & $\begin{array}{l}{[88,104-} \\
106]\end{array}$ \\
\hline$\left[\mathrm{Cr}_{3} \mathrm{~F}\left(\mathrm{H}_{2} \mathrm{O}\right)_{2} \mathrm{O}(\mathrm{btc})\right]_{3}(\mathrm{MIL}-100)$ & (1) & $\begin{array}{l}18 \mathrm{mmolg}^{-1} \text { vs. } 7.5 \mathrm{mmolg}^{-1} \mathrm{CH}_{4} \\
(303 \mathrm{~K}, 48.7 \text { bar })\end{array}$ & 62 vs. $19 \mathrm{CH}_{4}$ & $\mathrm{CO}_{2} / \mathrm{CH}_{4}$ & [109] \\
\hline$\left[\mathrm{Cr}_{3} \mathrm{~F}\left(\mathrm{H}_{2} \mathrm{O}\right)_{2} \mathrm{O}(\mathrm{bdc})\right]_{3}(\mathrm{MIL}-101)$ & (1) & $\begin{array}{l}40 \mathrm{mmolg}^{-1} \text { vs. } 12 \mathrm{mmol} \mathrm{g}^{-1} \mathrm{CH}_{4} \\
(303 \mathrm{~K}, 48.7 \text { bar) }\end{array}$ & 44 vs. $18 \mathrm{CH}_{4}$ & $\mathrm{CO}_{2} / \mathrm{CH}_{4}$ & [109] \\
\hline$\left[\mathrm{Ni}_{2}(\mathrm{pbmp})\right]$ & (1) & $\begin{array}{l}2.5 \mathrm{mmolg}^{-1}(304 \mathrm{~K}, 1 \mathrm{bar}), 6 \mathrm{mmolg}^{-1} \\
(15 \mathrm{bar})\end{array}$ & 35 vs. $15 \mathrm{CH}_{4}$ & $\mathrm{CO}_{2} / \mathrm{CH}_{4} ; \mathrm{CO}_{2} / \mathrm{N}_{2}$ & {$[110]$} \\
\hline$\left[\mathrm{Mg}_{2}(\mathrm{dobdc})\right]$ & (1) & $\begin{array}{l}23.6 \text { wt } \%(298 \mathrm{~K}, 0.1 \mathrm{~atm}), 35.2 \mathrm{wt} \% \\
(1 \mathrm{~atm}), 63 \mathrm{wt} \% \text { (50 bar) }\end{array}$ & $38-42$ vs. $20-22 \mathrm{CH}_{4}$ & $\mathrm{CO}_{2} / \mathrm{CH}_{4}$ & [111-113] \\
\hline$\left[\mathrm{Ni}_{2}(\mathrm{dobdc})\right]$ & $(1)$ & 51 wt \% (298 K, 50 bar $)$ & 41 & & [1 $111-113]$ \\
\hline$\left[\mathrm{Zn}_{3}(\mathrm{OH})(\mathrm{p}-\mathrm{cdc})_{2.5}\right]$ & (1) & $\begin{array}{l}0.566 \mathrm{mmolg}^{-1}(298 \mathrm{~K}, 0.5 \mathrm{bar}) \\
\text { vs. } 0.0754 \mathrm{mmolg}^{-1} \mathrm{CH}_{4}\end{array}$ & & $\begin{array}{l}\mathrm{CO}_{2} / \mathrm{CH}_{4}, 5-17^{1 \mathrm{AST}} \\
(0.5-15 \text { bar })\end{array}$ & {$[97,114]$} \\
\hline$\left[\mathrm{Co}_{4}\left(\mu-\mathrm{OH}_{2}\right)_{4}(\mathrm{mtb})_{2}\right]$ & (1) & $1.59 \mathrm{mmolg}^{-1}, 7.02 \mathrm{wt} \%(273 \mathrm{~K}, 1 \mathrm{~atm})$ & & $\mathrm{CO}_{2} / \mathrm{CH}_{4} ; \mathrm{CO}_{2} / \mathrm{N}_{2}$ & [115] \\
\hline$\left[\mathrm{Zn}(\mathrm{adc})(\mathrm{Bpe})_{0.5}\right]$ & $(2)$ & & & $\mathrm{CO}_{2} / \mathrm{CH}_{4} ; \mathrm{CO}_{2} / \mathrm{N}_{2}$ & [116] \\
\hline$\left[\mathrm{Ni}(\mathrm{cyclam})_{2}(\mathrm{mtb})\right]$ & $(2)$ & $2.53 \mathrm{mmolg}^{-1}, 11.2 \mathrm{wt} \%(195 \mathrm{~K}, 1 \mathrm{~atm})$ & & $\mathrm{CO}_{2} / \mathrm{CH}_{4} ; \mathrm{CO}_{2} / \mathrm{N}_{2}$ & [89] \\
\hline$\left[\mathrm{Zn}(\mathrm{bdc})(\mathrm{bpy})_{0.5}\right](\mathrm{MOF}-508 \mathrm{~b})$ & $(2)$ & $\begin{array}{l}\approx 6 \mathrm{mmolg}^{-1}, 26.0 \mathrm{wt} \% \text { vs. } 5.5 \mathrm{wt} \% \mathrm{~N}_{2} \\
\text { and } 3.2 \mathrm{wt} \% \mathrm{CH}_{4}(303 \mathrm{~K}, 4.5 \text { bar })\end{array}$ & $\begin{array}{l}14.9 \text { vs. } 5.6 \mathrm{~N}_{2} \\
\text { and } 5.1 \mathrm{CH}_{4}\end{array}$ & $\mathrm{CO}_{2} / \mathrm{CH}_{4} ; \mathrm{CO}_{2} / \mathrm{N}_{2}$ & [117] \\
\hline$[\mathrm{Mg}(\mathrm{tcpbda})]$ & $(1,2)$ & $\begin{array}{l}1.49 \mathrm{mmolg}^{-1}, 6.5 \mathrm{wt} \%(298 \mathrm{~K}, 1 \mathrm{~atm}) \\
\text { vs. } 0.45 \mathrm{mmolg}^{-1}, 0.73 \mathrm{wt} \% \mathrm{CH}_{4} \\
\text { and negligible } \mathrm{N}_{2}\end{array}$ & & $\mathrm{CO}_{2} / \mathrm{CH}_{4} ; \mathrm{CO}_{2} / \mathrm{N}_{2}$ & [118] \\
\hline$[\mathrm{Cr}(\mathrm{OH})(\mathrm{bdc})](\mathrm{MIL}-53(\mathrm{Cr}))$ & $(3)$ & $\begin{array}{l}8.5 \mathrm{mmolg}^{-1} \text { (10 bar) vs. } 2-3 \mathrm{mmolg}^{-1} \\
\mathrm{CH}_{4}(5-10 \text { bar })\end{array}$ & & $\mathrm{CO}_{2} / \mathrm{CH}_{4}$ & [119] \\
\hline Hydrated $[\mathrm{Cr}(\mathrm{OH})(\mathrm{bdc})]$ & $(3)$ & $\begin{array}{l}7.7 \mathrm{mmolg}^{-1}(304 \mathrm{~K}, 18 \mathrm{bar}) \\
\text { vs. } 0.2 \mathrm{mmolg}^{-1} \mathrm{CH}_{4}(20 \text { bar })\end{array}$ & & $\mathrm{CO}_{2} / \mathrm{CH}_{4}$ & [120] \\
\hline$\left[\mathrm{Co}(\mathrm{F}-\mathrm{pymo})_{2}\right]$ & $(3)$ & $7 \mathrm{mmolg}^{-1}$ ( $273 \mathrm{~K}, 20$ bar) vs. negligible $\mathrm{CH}_{4}$ & & $\mathrm{CO}_{2} / \mathrm{CH}_{4}$ & [121] \\
\hline$\left[\mathrm{Zn}(\mathrm{F}-\mathrm{pymo})_{2}\right]$ & (3) & $8 \mathrm{mmolg}^{-1}(273 \mathrm{~K}, 20$ bar $)$ vs. negligible $\mathrm{CH}_{4}$ & & $\mathrm{CO}_{2} / \mathrm{CH}_{4}$ & {$[121]$} \\
\hline$\left[\left(\mathrm{Ni}_{2} \mathrm{~L} 1\right)(\right.$ bptc $\left.)\right]$ (ethyl-bridged) & (3) & 9.3 wt \% (298 K, 1 atm), 15 wt \% (15 bar) & & $\begin{array}{l}\mathrm{CO}_{2} / \mathrm{CH}_{4} ; \mathrm{CO}_{2} / \mathrm{H}_{2} \\
\mathrm{CO}_{2} / \mathrm{N}_{2}\end{array}$ & [122] \\
\hline$\left[\left(\mathrm{Ni}_{2} \mathrm{~L} 2\right)(\right.$ bptc) $]$ (butyl-bridged) & (3) & 0 wt \% (298 K, 1 atm), 21 wt \% (15 bar) & & & [122] \\
\hline$\left[\mathrm{Zn}_{2}(\mathrm{bttb})\left(\mathrm{py}-\mathrm{CF}_{3}\right)_{2}\right]$ & $(4)$ & $\begin{array}{l}\approx 0.2 \mathrm{mmolg}^{-1}(298 \mathrm{~K}, 0.15 \mathrm{bar}) \\
\approx 3 \mathrm{mmolg}^{-1}(18 \mathrm{bar})\end{array}$ & & $\begin{array}{l}\mathrm{CO}_{2} / \mathrm{N}_{2}, \approx 40^{\mathrm{IAST}} \\
\mathrm{CO}_{2} / \mathrm{CH}_{4}, 6^{\mathrm{IAST}} \\
(298 \mathrm{~K})\end{array}$ & {$[123]$} \\
\hline$\left[\mathrm{Zn} \mathrm{n}_{2}(\mathrm{bttb})\right]$ & (1) & $\begin{array}{l}\approx 0.4 \mathrm{mmolg}^{-1}(298 \mathrm{~K}, 0.15 \mathrm{bar}) \\
\approx 5 \mathrm{mmolg}^{-1}(18 \mathrm{bar})\end{array}$ & & $\begin{array}{l}\mathrm{CO}_{2} / \mathrm{N}_{2}, \approx 23^{\mathrm{IAST}} \\
\mathrm{CO}_{2} / \mathrm{CH}_{4}, 4.5^{\mathrm{IAST}} \\
(298 \mathrm{~K})\end{array}$ & {$[123]$} \\
\hline$\left[\mathrm{H}_{3} \mathrm{O}\right]\left[\mathrm{Zn}_{7}\left(\mu_{3}-\mathrm{OH}\right)_{3}(\mathrm{bbs})_{6}\right](\mathrm{UoC}-1)$ & $(4)$ & $\begin{array}{l}2 \mathrm{mmolg}^{-1}(273 \mathrm{~K}, 1 \text { bar }) \text { vs. } \\
0.57 \mathrm{mmolg}^{-1} \mathrm{CH}_{4} \text { and negligible } \\
\mathrm{N}_{2} \text { and } \mathrm{H}_{2}\end{array}$ & & $\begin{array}{l}\mathrm{CO}_{2} / \mathrm{CH}_{4} ; \mathrm{CO}_{2} / \mathrm{N}_{2} \\
\mathrm{CO}_{2} / \mathrm{H}_{2}\end{array}$ & {$[124]$} \\
\hline$\left[\mathrm{Al}(\mathrm{OH})\left(\mathrm{NH}_{2} \mathrm{bdc}\right)\right]$ & $(3,4)$ & $\begin{array}{l}2.3 \mathrm{mmolg}^{-1}, 10 \mathrm{wt} \% \text { ( } 303 \mathrm{~K}, 5 \text { bar), } \\
6.7 \mathrm{mmolg}^{-1}, 30 \mathrm{wt} \% \text { (13 bar) } \\
\text { vs. } 2.4 \mathrm{mmolg}^{-1} \mathrm{CH}_{4} \text { (30 bar) }\end{array}$ & 38.4 vs. $20 \mathrm{CH}_{4}$ & $\mathrm{CO}_{2} / \mathrm{CH}_{4}$ & {$[94,125]$} \\
\hline$[\mathrm{Al}(\mathrm{OH})(\mathrm{bdc})](\mathrm{MIL}-53(\mathrm{Al}))$ & (3) & 10 wt \% (298 K, 1 atm) & 20.1 vs. $20 \mathrm{CH}_{4}$ & $\mathrm{CO}_{2} / \mathrm{CH}_{4}$ & {$[25]$} \\
\hline$\left[\mathrm{Ni}_{2}\left(\mathrm{NH}_{2} \mathrm{bdc}\right)_{2}(\right.$ dabco $\left.)\right]$ & (4) & 14 wt \% (298 K, 1 atm), 60 wt \% (25 atm) & & & [126] \\
\hline$\left[\mathrm{Ni}_{2}(\mathrm{bdc})_{2}(\mathrm{dabco})\right]$ & & 10 wt \% (298 K, 1 atm) & & & [126] \\
\hline$\left[\ln (\mathrm{OH})\left(\mathrm{NH}_{2} \mathrm{bdc}\right)\right]$ & $(4)$ & 8 wt \% (298 K, 1 atm) & & & [126] \\
\hline$[\ln (\mathrm{OH})(\mathrm{bdc})]$ & & 4 wt \% (298 K, 1 atm) & & & [126] \\
\hline
\end{tabular}


Table 2: (Continued)

\begin{tabular}{|c|c|c|c|c|c|}
\hline Material|[a] & Category & 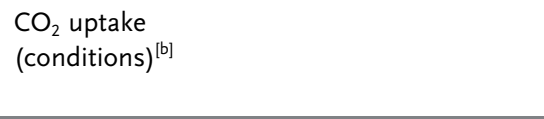 & $\begin{array}{l}-\Delta H_{\text {ads }} \\
{\left[\mathrm{k} \mathrm{mol}^{-1}\right]^{[c]}}\end{array}$ & $\begin{array}{l}\text { Separation } \\
\text { application, } \\
\text { Selectivity }{ }^{[d]}\end{array}$ & Ref. \\
\hline $\mathrm{HCu}\left[\left(\mathrm{Cu}_{4} \mathrm{Cl}\right)_{3}(\mathrm{BTTri})_{8}(\mathrm{en})_{5}\right]$ & (4) & $\begin{array}{l}\left.0.366 \mathrm{mmolg}^{-1}, 1.6 \mathrm{wt} \% \text { (0.06 atm, } 298 \mathrm{~K}\right) \\
1.27 \mathrm{mmol} \mathrm{g}^{-1}, 5.5 \mathrm{wt} \% \text { (1 bar) }\end{array}$ & 90 & $\mathrm{CO}_{2} / \mathrm{N}_{2}$ & [127] \\
\hline $\mathrm{HCu}\left[\left(\mathrm{Cu}_{4} \mathrm{Cl}\right)_{3}(\mathrm{BTTri})_{8}\right]$ & (1) & $\begin{array}{l}0.277 \mathrm{mmolg}^{-1}, 0.92 \mathrm{wt} \%(0.06 \mathrm{~atm}, 298 \mathrm{~K}) \\
3.24 \mathrm{mmolg}^{-1}, 14.3 \mathrm{wt} \%(1 \mathrm{~atm})\end{array}$ & 21 & $\mathrm{CO}_{2} / \mathrm{N}_{2}$ & [127] \\
\hline Activated carbon-MAXSORB & [e] & $\begin{array}{l}0.5 \mathrm{mmolg}^{-1}(1 \mathrm{~atm}) \\
25 \mathrm{mmolg}^{-1}(298 \mathrm{~K}, 30 \mathrm{bar})\end{array}$ & 14.6 & & {$[45,128]$} \\
\hline BPL carbon & [e] & $\begin{array}{l}\approx 0.4 \mathrm{mmolg}^{-1}(1 \mathrm{~atm}) \\
4 \mathrm{mmolg}^{-1}(10 \mathrm{~atm})\end{array}$ & 24.3 & $\mathrm{CO}_{2} / \mathrm{CH}_{4} ; \mathrm{CO}_{2} / \mathrm{N}_{2}$ & {$[45,98]$} \\
\hline Zeolite 13X & [e] & $\begin{array}{l}3.3 \mathrm{mmol} \mathrm{g}^{-1}(323 \mathrm{~K}, 1 \mathrm{~atm}), 6.9 \mathrm{mmol} \mathrm{g}^{-1} \\
(295 \mathrm{~K}, 15 \mathrm{bar}), 7.4 \mathrm{mmolg}^{-1}(298 \mathrm{~K}, 32 \mathrm{bar})\end{array}$ & 49 & & {$[51,88,106]$} \\
\hline
\end{tabular}

[a] Abbreviations: $b t b=1,3,5$-benzenetribenzoate, $b d c=1,4$-benzenedicarboxylate, $\mathrm{NH}_{2}$ bdc $=2$-amino-1,4-benzenedicarboxylate, fma $=$ fumarate, bpdc $=$ biphenyl-4,4'-dicarboxylate, dpni $=N, N^{\prime}$-di (4-pyridyl)-1,4,5,8-napthalenetetracarboxydiimide, bpy $=4,4^{\prime}$-bipyridine, BPnDC $=$ benzophenone4,4'-dicarboxylate, $\quad n d c=1,4$-napthalenedicarboxylate, $\quad$ btc $=1,3,5$-benezenetricarboxylate, $\quad \mathrm{pbmp}=N, N^{\prime}$-piperazinebismethylenephosphonate, $\mathrm{H}_{4}$ dobdc $=2,5$-dihydroxyterephthalic acid, $\mathrm{p}$-cdc ${ }^{2-}=$ deprotonated form of 1,12-dihydroxydicarbonyl-1,12-dicarba-closo-dodecaborane, $\mathrm{mtb}=$ methanetetrabenzoate, $\mathrm{H}_{2}$ tcpbda $=N, N, N^{\prime}, N^{\prime}$-tetrakis (4-carboxyphenyl)-biphenyl-4,4'-diamine, adc $=4,4^{\prime}$-azobenzenedicarboxylate, Bpe $=$ trans-bis (4-pyridyl)ethylene), cyclam $=1,4,8,11$-tetraazacyclotetradecane, $\mathrm{F}$-pymo $=5$-fluoropyrimidin-2-olate, $\mathrm{L} 1$ and $\mathrm{L} 2=$ ethyl- and butyl-bridged $\mathrm{Ni}_{2} \mathrm{macrocyclic}$ complexes shown in Figure 5 b, bptc $=1,1^{\prime}$-biphenyl-3,3',5,5'-tetracarboxylate, bttb $=4,4^{\prime}, 4^{\prime \prime}, 4^{\prime \prime \prime}$-benzene-1,2,4,5-tetrayltetrabenzoate, bbs $=$ dianion of 4,4'-bibenzoic acid-2,2'-sulfone, dabco =1,4-diazabicyclo[2.2.2]octane, $\mathrm{H}_{3} \mathrm{BTTri}=1,3,5$-tri $(1 \mathrm{H}-1,2,3$-triazol-4-yl) benzene, 4'-tert-butyl-biphenyl-3,5dicarboxylate. [b] Uptakes of $\mathrm{CH}_{4}, \mathrm{~N}_{2}$ and $\mathrm{H}_{2}$ shown where appropriate for comparison. [c] $\Delta H_{\text {ads }}=$ Enthalpy of adsorption for $\mathrm{CO}_{2}$. The initial isosteric heat of adsorption is reported unless otherwise stated. [d] Reported selectivities from single adsorption isotherms, unless otherwise stated: IAST = calculated using IAST theory from the experimental single adsorption isotherms assuming equimolar gas mixtures. [e] Benchmark material.

ZIFs with a range of pore aperture metrics. Functionalization of the imidazolate and benzimidazolate linkers was also shown to permit fine-tuning of the interactions between the pore walls and guest molecules, thereby varying the selectivity of adsorption. Importantly, in contrast to many metal-organic frameworks, ZIFs exhibit high thermal stabilities and chemical stability in refluxing aqueous and organic media, which are required for practical separations processes. ${ }^{[99]}$ In particular, the stability of a framework toward long-term exposure to water vapor is a critical issue in determining its suitability for $\mathrm{CO}_{2}$ capture from flue gas. ${ }^{[102]}$

\subsubsection{Frameworks Containing Open Metal Sites}

The presence of coordinatively unsaturated metal sites in MOFs also provides a mechanism for the enhanced separation of (quadru)polar/non-polar gas pairs such as $\mathrm{CO}_{2} / \mathrm{CH}_{4}$. Amongst the reported examples, $\left[\mathrm{Cu}_{3}(\mathrm{btc})_{2}\right]$ (HKUST-1, $\mathrm{btc}^{3-}=1,3,5$-benzenetricarboxylate), which consists of paddlewheel $\mathrm{Cu}_{2}\left(\mathrm{COO}^{-}\right)_{4}$ units connected through btc ${ }^{3-}$ ligands, is amongst the most extensively studied. ${ }^{[103]}$ The results for the $\mathrm{CO}_{2}$ uptake capacities reported by various groups differ significantly ${ }^{[88,104-106]}$ but the highest uptake capacity has been reported as $12.7 \mathrm{mmolg}^{-1}$ at $15 \mathrm{bar}$ and $298 \mathrm{~K}^{\left[{ }^{[106]}\right.}$ The increase in the $\mathrm{CO}_{2}$ adsorption capacity with increasing pressure and decreasing temperature is indicative of physisorption in a microporous solid, and indicates the potential suitability for application of the material in pressure or temperature swing adsorption processes. The framework preferentially adsorbs $\mathrm{CO}_{2}$ over both $\mathrm{CH}_{4}$ and $\mathrm{N}_{2}$ with a moderate enthalpy of adsorption $\left(-30\right.$ to $\left.-35 \mathrm{~kJ} \mathrm{~mol}^{-1}\right) \cdot{ }^{[106]}$ The mechanism of adsorption can be described by $\mathrm{CO}_{2}$ coordination to the metal center in an end-on fashion, i.e., $\mathrm{O}=\mathrm{C}=\mathrm{O} \cdots \mathrm{Cu}^{2+} \cdot[107]$
The presence of water in such frameworks can lead to striking enhancements in their $\mathrm{CO}_{2}$ capture abilities. Recent experimental and computational studies ${ }^{[108]}$ showed a significant increase in the $\mathrm{CO}_{2}$ adsorption capacity as well as enhanced $\mathrm{CO}_{2} / \mathrm{CH}_{4}$ and $\mathrm{CO}_{2} / \mathrm{N}_{2}$ selectivities in the $\left[\mathrm{Cu}_{3}(\mathrm{btc})_{2}\right]$ framework containing $4 \mathrm{wt} \%$ water. ${ }^{[06]}$ In this case, the quadrupole moment of $\mathrm{CO}_{2}$ interacts with the electric field created by the water molecules which are coordinated to the open $\mathrm{Cu}^{2+}$ sites. ${ }^{[106]}$ The working capacity of the hydrated $\left[\mathrm{Cu}_{3}(\mathrm{btc})_{2}\right]$ material for $\mathrm{CO}_{2}$ capture is almost four times that of the benchmark material zeolite $13 X{ }^{[106]}$ It is not clear, however, if such an enhancement will extend to other frameworks with exposed metal cation sites, and in general there is a need for further study of the effects of water vapor on performance.

$\mathrm{CO}_{2}$ adsorption has been investigated in the MIL (Matériaux Institut Lavoisier) series of frameworks $\left[\mathrm{Cr}_{3} \mathrm{~F}\right.$ $\left.\left(\mathrm{H}_{2} \mathrm{O}\right)_{2} \mathrm{O}(\mathrm{btc})\right]_{3} \quad\left(\mathrm{MIL}-100, \quad \mathrm{SA}_{\text {Langmuir }}=3100 \mathrm{~m}^{2} \mathrm{~g}^{-1}\right) \quad$ and $\left[\mathrm{Cr}_{3} \mathrm{~F}\left(\mathrm{H}_{2} \mathrm{O}\right)_{2} \mathrm{O}(\mathrm{bdc})\right]_{3}\left(\mathrm{MIL}-101, \mathrm{SA}_{\mathrm{BET}}=4100 \mathrm{~m}^{2} \mathrm{~g}^{-1}\right)$ which exhibit high surface areas and large pore sizes in addition to coordinatively unsaturated $\mathrm{Cr}^{3+}$ sites. ${ }^{[109]}$ Both frameworks possess higher capacities for $\mathrm{CO}_{2}$ relative to $\mathrm{CH}_{4}$, as well as moderately high enthalpies of adsorption for $\mathrm{CO}_{2}$ at zero coverage (-44 and $-63 \mathrm{~kJ} \mathrm{~mol}^{-1}$ for MIL-100 and MIL-101, respectively). The mechanism of adsorption involves end-on coordination (i.e., $\mathrm{O}=\mathrm{C}=\mathrm{O} \cdots \mathrm{Cr}^{3+}$ ). A recent study has demonstrated that the Dual Site Langmuir model is useful for understanding adsorption behaviour in frameworks such as MIL-101 which involve heterogeneity due to the presence of open metal sites. ${ }^{[23]}$ A nearly linear correlation was also uncovered between the polarizability of the gas molecule and the resulting enthalpy of adsorption of the adsorbate in the framework. This finding provides an important design consideration for gas separations in materials containing exposed metal cation sites. 
The influence of the identity of the metal center on the capacity and selectivity of $\mathrm{CO}_{2}$ adsorption has been systematically studied in the series of isostructural frameworks $\left[\mathrm{M}_{2}(\right.$ dobdc $\left.)\left(\mathrm{H}_{2} \mathrm{O}\right)_{2}\right]\left(\mathrm{M}=\mathrm{Ni}, \mathrm{Co}, \mathrm{Zn}, \mathrm{Mg}, \mathrm{Mn} ; \mathrm{H}_{4}\right.$ dobdc $=2,5-$ dihydroxyterephthalic acid). ${ }^{[111]}$ As shown in Figure 4, these

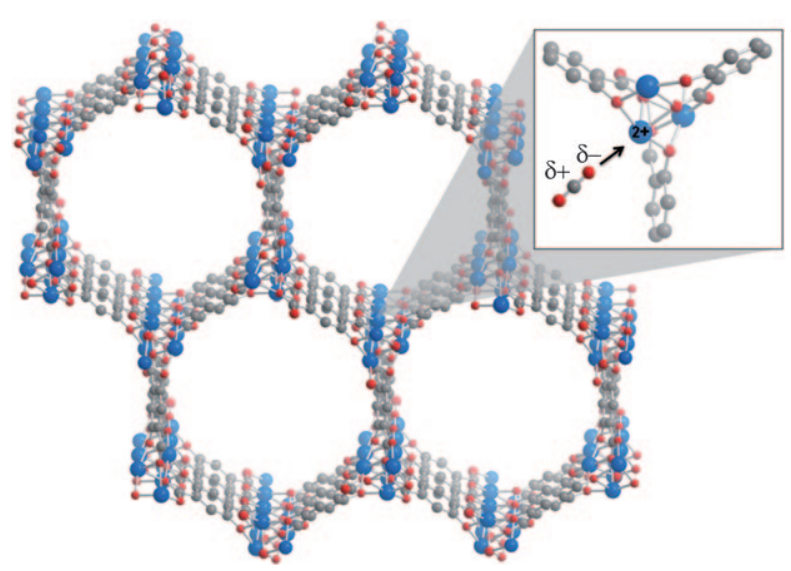

Figure 4. The crystal structure of $\left[\mathrm{Mg}_{2}(\mathrm{dobdc})\right]$ viewed along the onedimensional channels. ${ }^{[13]}$ The inset shows the charge-induced interaction between one of the open $\mathrm{Mg}^{2+}$ coordination sites and a $\mathrm{CO}_{2}$ molecule. Blue, red, and gray spheres represent $\mathrm{Mg}, \mathrm{O}$, and $\mathrm{C}$ atoms, respectively. Hydrogen atoms are omitted for clarity.

frameworks are characterized by a honeycomb structure with one-dimensional channels of 11-12 $\AA$ diameter, and a high concentration of open metal sites which are generated upon removal of the coordinated water molecules. The $\mathrm{CO}_{2}$ uptake of $\left[\mathrm{Mg}_{2}(\right.$ dobdc $\left.)\right]$ is more than double that for any other member of the series, ${ }^{[112]}$ and the high enthalpy of adsorption $\left(-47 \mathrm{~kJ} \mathrm{~mol}^{-1}\right)$ relative to the isostructural frameworks $(-41$ and $-37 \mathrm{~kJ} \mathrm{~mol}^{-1}$ for $\mathrm{M}=\mathrm{Ni}$ and $\mathrm{Co}$, respectively) suggests preferential adsorption of $\mathrm{CO}_{2}$ on $\mathrm{Mg}^{2+}$. Indeed, infrared studies confirmed an end-on coordination mode for $\mathrm{CO}_{2}$, with the increased ionic character of the $\mathrm{Mg}^{2+}-\mathrm{O}$ interaction accounting for the high adsorption capacity. ${ }^{[12,113,129]}$

Since the dynamic separation capacity of framework materials provides a more reliable measure of their separation ability, breakthrough experiments were performed on $\left[\mathrm{Mg}_{2}\right.$ (dobdc) $]$ and $\left[\mathrm{Ni}_{2}\right.$ (dobdc) $]$ using $\mathrm{CO}_{2} / \mathrm{CH}_{4}$ and $\mathrm{CO}_{2} / \mathrm{N}_{2}$ mixtures. ${ }^{[13]}$ Such measurements are performed by exposing the material to a mixed gas stream (e.g., $80 \% \mathrm{CH}_{4}, 20 \%$ $\mathrm{CO}_{2}$ ), and detecting the appearance or "breakthrough" of $\mathrm{CO}_{2}$. For both frameworks, quantitative separation of $\mathrm{CO}_{2}$ from $\mathrm{N}_{2}$, and substantial retention of $\mathrm{CO}_{2}$ from mixtures with $\mathrm{CH}_{4}$ was observed. A comparison of the dynamic separation capacity with that of a benchmark material such as Zeolite $13 \mathrm{X}$ under the same conditions, revealed that the framework exhibited superior performance.

Highly selective $\mathrm{CO}_{2}$ adsorption is also observed in cases where a material possesses a number of different potential adsorption sites. For example, the nickel phosphonate framework $\left[\mathrm{Ni}_{2}(\mathrm{pbmp})\right]$ (where $\mathrm{pbmp}^{4-}=N, N^{\prime}$-piperazinebismethylenephosphonate) contains three crystallographically distinct coordinatively unsaturated metal centers, as well as $\mathrm{P}=\mathrm{O}$ groups from the organic linkers that project into the pores. ${ }^{[110]}$
IAST calculations have also been employed to predict the selectivity for $\mathrm{CO}_{2} / \mathrm{CH}_{4}$ mixture adsorption in frameworks such as $\left[\mathrm{Zn}_{3}(\mathrm{OH})(\mathrm{p}-\mathrm{cdc})_{2.5}(\mathrm{DMF})_{4}\right] \quad\left(\mathrm{p}-\mathrm{cdcH}_{2}=1,12\right.$-dihydroxydicarbonyl-1,12-dicarba-closo-dodecaborane) with and without coordinatively unsaturated $\mathrm{Zn}^{2+}$ sites, i.e., with and without coordinated DMF molecules. ${ }^{[97,114]}$ As expected, the fully desolvated framework containing open metal sites exhibited a higher adsorption capacity due to the favorable interactions between the partial charges on the framework and the quadrupole moment of $\mathrm{CO}_{2}$. From the single component adsorption isotherms, IAST predicts that the selectivities for the solvated, and desolvated frameworks approach one another at higher pressures (up to 20 bar), since the enhanced adsorption of $\mathrm{CO}_{2}$ at open metal sites becomes less important as the pores are filled with molecules. The isosteric heat of adsorption for the material containing open metal sites also decreases significantly after full occupation. ${ }^{[111]}$

It must be noted that the morphology of the sample has been shown to significantly affect gas adsorption. For example, three samples of the carborane-based framework $\left[\mathrm{Co}_{4}(\mathrm{OH})_{2}(\mathrm{p}-\mathrm{cdc})_{3}(\mathrm{DMF})_{2}\right]^{[130]}$ were prepared using slight variations in the reaction conditions and co-solvents to generate block-like single crystals, polycrystalline tetragonal microrods and a less-crystalline material in the form of agglomerates. The different porosities, crystallinity, and internal surface areas of the samples led to variable $\mathrm{CO}_{2}$ uptake data.

Other frameworks such as $\left[\mathrm{Co}_{4}\left(\mu-\mathrm{OH}_{2}\right)_{4}(\mathrm{mtb})_{2}\right]$, which is based on the tetrahedral organic linker $\mathrm{mtb}^{4-}$ (methanetetrabenzoate) and contains one coordinatively unsaturated site per metal center, also show selective $\mathrm{CO}_{2}$ adsorption over $\mathrm{CH}_{4}$ and $\mathrm{N}_{2} \cdot{ }^{[115]}$ The open $\mathrm{Co}^{2+}$ sites endow the framework with exceptional selectivity for $\mathrm{O}_{2}$ over $\mathrm{N}_{2}$, which has relevance to air separation processes for oxyfuel combustion, amongst others.

\subsubsection{Interpenetration as a Strategy for Selective Adsorption}

Interpenetrated frameworks have potential for application in gas separations processes since their pore sizes often lie in the range for industrially important gas separations, as shown in Table 1. Their adsorption capacities however, are often inferior to those observed for non-interpenetrated structures.

A molecular sieving affect was invoked to explain the selective sorption of $\mathrm{CO}_{2}$ over $\mathrm{CH}_{4}$ in $\left[\mathrm{Zn}(\operatorname{adc})(\mathrm{Bpe})_{0.5}\right]$ $\left(\mathrm{adc}^{2-}=4,4^{\prime}\right.$-azobenzenedicarboxylate, Bpe = trans-bis(4-pyridyl)ethylene), which comprises a triply interpenetrated cubic net with pores of $3.4 \times 3.4 \AA$, and a surface area of $100 \mathrm{~m}^{2} \mathrm{~g}^{-1} \cdot{ }^{[16]}$ The four-fold interpenetrating diamondoid framework [Ni(cyclam $\left.)_{2}(\mathrm{mtb})\right]($ cyclam $=1,4,8,11$-tetraazacyclotetradecane), which is characterized by one-dimensional channels with dimensions of $2.05 \times 2.05 \AA$, and a BET surface area of $141 \mathrm{~m}^{2} \mathrm{~g}^{-1[89]}$ also shows selective $\mathrm{CO}_{2}$ adsorption over $\mathrm{N}_{2}$ and $\mathrm{CH}_{4}$. In both cases, the origin of the selectivity was ascribed to the smaller kinetic diameter of $\mathrm{CO}_{2}$ (relative to the other two gases) and its enhanced interactions with the host framework due to its quadrupole moment. 
While adsorption measurements were performed using single component sorption isotherms in the aforementioned cases, the doubly interpenetrated framework [ $\mathrm{Zn}(\mathrm{bdc})$ (bpy) $)_{0.5}$ (MOF-508b) with one-dimensional micropores of $4.0 \times 4.0 \AA$ was the first examined for the separation and capture of $\mathrm{CO}_{2}$ from binary $\mathrm{CO}_{2} / \mathrm{N}_{2}$ and $\mathrm{CO}_{2} / \mathrm{CH}_{4}$ and ternary $\mathrm{CO}_{2} / \mathrm{CH}_{4} / \mathrm{N}_{2}$ mixtures by fixed-bed adsorption. ${ }^{[117]}$ Breakthrough measurements confirmed that $\mathrm{CO}_{2}$ was preferentially adsorbed over $\mathrm{N}_{2}$ and $\mathrm{CH}_{4}$ due to a molecular sieving effect. The breakthrough fixed-bed adsorption of the binary and ternary mixtures revealed selectivity factors of 3-4 for $\mathrm{CO}_{2} /$ $\mathrm{CH}_{4}$ and 4-6 for $\mathrm{CO}_{2} / \mathrm{N}_{2}$. These were found to improve with increasing partial pressure and decreasing temperature, suggesting that further selectivity enhancements could be achieved at lower temperatures and higher pressures.

Preferential $\mathrm{CO}_{2}$ adsorption has been observed for frameworks which combine the properties of interpenetration with the presence of coordinatively unsaturated sites. ${ }^{[118]}$ The framework $[\mathrm{Mg}($ tcpbda $)] \quad\left(\mathrm{H}_{2} \mathrm{tcpbda}=N, N, N^{\prime}, N^{\prime}\right.$-tetrakis(4-carboxyphenyl)-biphenyl-4,4'-diamine) for example, exhibits good $\mathrm{CO}_{2}$ adsorption compared with $\mathrm{CH}_{4}$ and $\mathrm{N}_{2}{ }^{[118]}$

\subsubsection{Flexible Frameworks}

In contrast to the rigid frameworks discussed above which retain their porosity upon adsorption and desorption, flexible and dynamic frameworks collapse upon removal of guest solvent molecules, but restore their porous structures by adsorption of gas molecules at high pressures. ${ }^{[131]}$ The adsorption isotherms are typically characterized by a distinct step, at which point the material "opens up" as gas molecules enter the pores. ${ }^{[15]}$ In some striking cases, almost no adsorption occurs below a threshold or "gate-opening" pressure for the non-porous structural phase, until the pores of the material become accessible and permit significant adsorption. The desorption isotherms are also typically characterized by hysteresis. The caveat must be added that while flexible frameworks operating by a gate-opening mechanism appear to be excellent candidates for gas separations when comparing single gas isotherms, such materials may not perform well for gas mixtures. If one component of a mixture triggers pore opening through framework breathing, then all components will be permitted to enter the structure, thereby negating the perceived selectivity. This is a serious potential drawback in the utility of such breathing frameworks which underscores the need for measurements using gas mixtures.

b)
While high surface area frameworks are often sought for gas adsorption to achieve maximum loadings, the penalty in many cases may be a lack of selectivity which is required for gas separations applications. The flexible interpenetrated framework shown in Figure $5 \mathrm{a}$ is based on 4,4'-bipyridine and the tetrahedral organic linker tetrakis[4-(carboxyphenyl)oxamethyl]methane. ${ }^{[132]}$ The material was characterized by a step in the $\mathrm{CO}_{2}$ isotherm at ca. 10 bar, and a maximum adsorption of $7.1 \mathrm{mmol} \mathrm{g}^{-1}$ at 30 bar. The capacity is well below that obtained for MOF-177 $\left(35 \mathrm{mmolg}^{-1}\right)$ and activated carbon (MAXSORB, $25 \mathrm{mmol} \mathrm{g}^{-1}$ ), but comparable to that of zeolite $13 \mathrm{X}\left(7.4 \mathrm{mmol} \mathrm{g}^{-1}\right)$ at the same pressure. ${ }^{[88]}$ At pressures in the range $0-1$ bar relevant to flue streams, the framework exhibited a significantly greater uptake of $\mathrm{CO}_{2}$ compared with $\mathrm{N}_{2}$, and at pressures up to 20 bar relevant to syngas separation, virtually no $\mathrm{H}_{2}$ adsorption was detected. The mechanism for the selectivity enhancement was ascribed to size/shape discrimination, however, it appears that the $\mathrm{CO}_{2}$ molecules must also exhibit a preferential electrostatic interaction with the material, possibly with the oxygen atoms of the linker.

The observation of one or more distinct steps in the adsorption isotherms represents a key feature of flexible a)<smiles>O=C(O)c1ccc(OCC(COc2ccc(C(=O)O)cc2)(COc2ccc(C(=O)O)cc2)COc2ccc(C(=O)O)cc2)cc1</smiles>

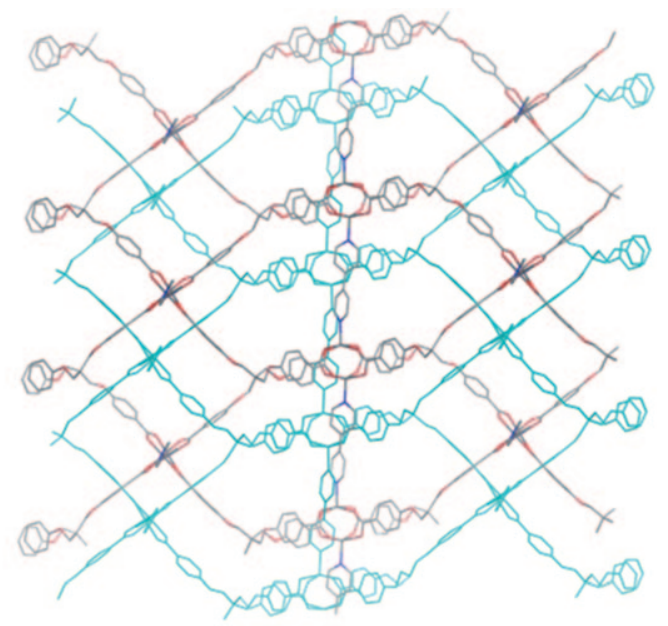

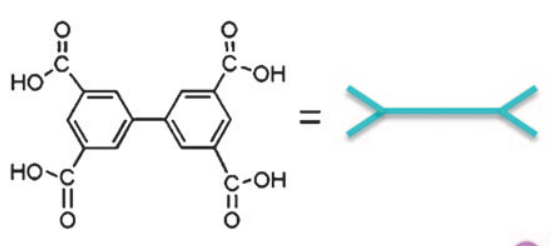
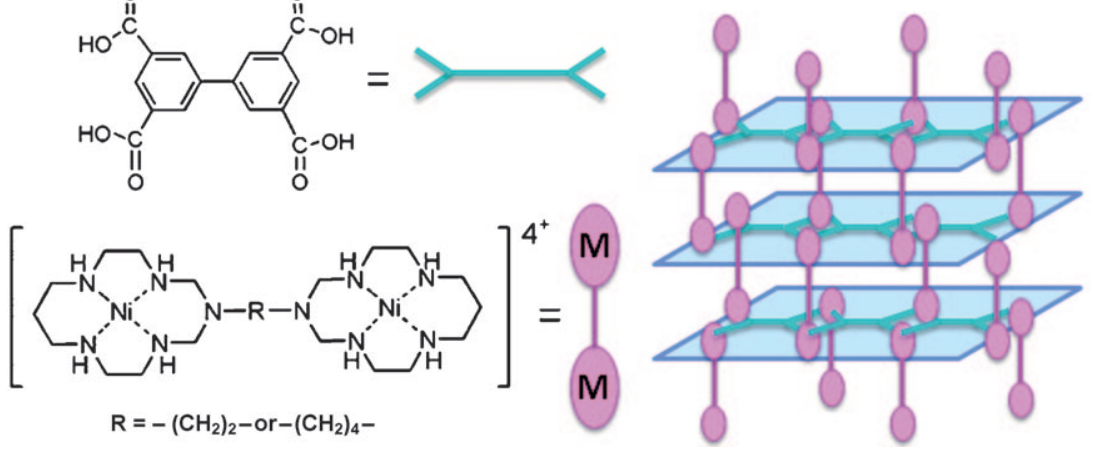

Figure 5. Examples of flexible metal-organic frameworks. a) The tetrahedral organic linker tetrakis[4-(carboxyphenyl)oxamethyl]methane and the flexible interpenetrated framework based upon this ligand with $\mathrm{Zn}_{2}$ paddlewheel cluster units and 4,4'-bipyridine. ${ }^{[132]}$ In one portion of the structure, blue, red, and gray sticks represent the $\mathrm{N}, \mathrm{O}$, and $\mathrm{C}$ atoms, respectively, while the interpenetrated framework is shown in cyan. Hydrogen atoms are omitted for clarity. b) The bptc ligand and a schematic diagram of the $\left[\left(\mathrm{Ni}_{2} \mathrm{~L}\right)(\mathrm{bptc})\right]$ framework, where $\mathrm{Ni}_{2} \mathrm{~L}$ represents the ethylor butyl-bridged bismacrocyclic complexes shown. ${ }^{[122]}$ 
frameworks. The MIL-53 series has been extensively investigated for high-pressure $\mathrm{CO}_{2}$ and $\mathrm{CH}_{4}$ adsorption. ${ }^{[119,133-137]}$ The framework $[\mathrm{Cr}(\mathrm{OH})(\mathrm{bdc})](\mathrm{MIL}-53(\mathrm{Cr}))$, for example, exhibits a small $\mathrm{CO}_{2}$ uptake below 5 bar, however, a distinct step is observed in the adsorption isotherm as the structure opens up to provide for a higher gas uptake. ${ }^{[119]}$ This step is absent in the corresponding isotherm for $\mathrm{CH}_{4}$ which exhibits a gradual uptake over the same pressure range. On the basis of diffuse reflectance infrared spectroscopy ${ }^{[133]}$ microcalorimetry, and Monte Carlo simulations, ${ }^{[136]}$ the phenomenon was ascribed to a breathing effect in the flexible porous solid which occurs in the presence of $\mathrm{CO}_{2}$ (but not $\left.\mathrm{CH}_{4}\right) \cdot{ }^{[68]} \mathrm{An}$ indepth study of MIL-53(Cr) upon adsorption of binary $\mathrm{CO}_{2} /$ $\mathrm{CH}_{4}$ mixtures showed that the breathing effect is mainly controlled by the partial pressure of $\mathrm{CO}_{2}$, with $\mathrm{CH}_{4}$ having only a minor influence on the extent of the transition between the open and closed forms. ${ }^{[138]}$ Breakthrough experiments revealed that the $\mathrm{CO}_{2} / \mathrm{CH}_{4}$ selectivity decreases from 15 to 4 as the $\mathrm{CO}_{2}$ partial pressure increases from 0-0.25 (for a 75:25 mixture). This low selectivity for $\mathrm{CO}_{2}$ at high pressure, in addition to the large hysteresis is such that the desorption occurs at a lower pressure than is desirable for a pressure swing adsorption application, for example.

The presence of water leads to a drastic increase in the $\mathrm{CO}_{2}$ uptake relative to $\mathrm{CH}_{4}$ in the MIL-53(Cr) framework. ${ }^{[120]}$ The adsorption of $\mathrm{CO}_{2}$ on the hydrated framework occurred to a small extent only at pressures up to $10 \mathrm{bar}$, while a distinct uptake occurred over a broad pressure range of $12-18$ bar as the hydrated structure opens to accommodate gas molecules. It was inferred that the presence of water within the framework impedes the entry of $\mathrm{CO}_{2}$ molecules at low pressures prior to the total opening of the structure at higher pressures. The hydrated framework exhibited negligible adsorption of $\mathrm{CH}_{4}$ due to the repulsive effect of the free water in the pores that impede or block entry to the non-polar molecules. From a practical perspective, the results suggest that a pre-adsorber column, which is often employed for water removal prior to $\mathrm{CO}_{2} / \mathrm{CH}_{4}$ separation, is unnecessary given the enhanced separation performance for the hydrated flexible framework material.

From these examples, it is evident that the breathing behavior of flexible frameworks is highly dependent on cooperative effects which arise from the favorable interaction between the quadrupolar $\mathrm{CO}_{2}$ molecule with the polar surface of the framework. For example, the frameworks $\left[\mathrm{M}(\mathrm{F}-\text { pymo })_{2}\right](\mathrm{M}=\mathrm{Co}, \mathrm{Zn}, \mathrm{F}$-pymo $=5$-fluoropyrimidin-2olate) were shown to exhibit highly selective adsorption of $\mathrm{CO}_{2}$ over $\mathrm{CH}_{4}$ due to preferential $\mathrm{CO}_{2}$ interactions with the fluorine groups. ${ }^{[121]}$ Highly selective $\mathrm{CO}_{2}$ capture (over $\mathrm{N}_{2}, \mathrm{H}_{2}$, and $\mathrm{CH}_{4}$ ) has also been observed in the flexible frameworks [(Ni $\left.\mathrm{Ni}_{2} \mathrm{~L}\right)($ bptc) $]$, where $\mathrm{Ni}_{2} \mathrm{~L}$ represents the ethyl- (L1) or butyl-bridged (L2) $\mathrm{Ni}^{2+}$ bismacrocyclic complexes and bptc is 1,1'-biphenyl-3,3',5,5'-tetracarboxylate (Figure 5b). ${ }^{[122]}$ The nature and length of the alkyl linker was also shown to modulate the degree of structural flexibility, leading to different gate opening pressures for the ethyl- and butylbridged frameworks.

As well as pressure, external stimuli such as temperature can be used to induce gating effects, particularly in frameworks which possess graphitic-type structures such as
$\left[\mathrm{M}(\text { bpy })_{2}\left(\mathrm{BF}_{4}\right)_{2}\right]\left(\mathrm{M}=\mathrm{Cu}, \mathrm{Ni}\right.$; bpy $=4,4^{\prime}$-bipyridine; $\mathrm{BF}_{4}^{-}=$ tetrafluoroborate $)^{[139]}$ and $\left[\mathrm{M}(\mathrm{bpy})_{2}\left(\mathrm{CF}_{3} \mathrm{SO}_{3}\right)_{2}\right](\mathrm{M}=\mathrm{Co}, \mathrm{Cu}$; bpy $=4,4^{\prime}$-bipyridine $) .{ }^{[139,140]}$ Here, each octahedral metal center is coordinated by four $\mathrm{N}$ atoms from bpy ligands in equatorial positions and two $\mathrm{BF}_{4}{ }^{-}$or $\mathrm{CF}_{3} \mathrm{SO}_{3}{ }^{-}$anions in axial positions to form two-dimensional square-grid sheets. In the case of $\left[\mathrm{Cu}(\mathrm{bpy})_{2}\left(\mathrm{BF}_{4}\right)_{2}\right]$, negligible $\mathrm{CO}_{2}$ adsorption occurs up to a pressure of 0.7 bar at $298 \mathrm{~K}$, at which point the interlayer spacing increases to accommodate the gas molecules. By comparison, relatively larger, non-polar $\mathrm{CH}_{4}$ molecules require a higher pressure of 4.5 bar. Since the "gate opening pressure" can be tuned with temperature, a temperature adsorption swing approach could be employed to achieve the separation on an industrial platform.

Mesh-adjustable molecular sieves (MAMS) constitute another class of materials for gas separations and are based on temperature induced gating phenomena. ${ }^{[141]}$ With the caveat added previously about measurements on single gas adsorption isotherms for flexible frameworks, MAMS represent a case where the dynamics of substituents at pore openings allow some molecules to pass but not others. On this basis, these materials are likely to be more viable for gas separations applications relative to many of the aforementioned flexible frameworks.

MAMS are represented by the isostructural series based on 4'-tert-butyl-biphenyl-3,5-dicarboxylic acid and $\mathrm{M}_{2-}$ $\left(\mathrm{COO}^{-}\right)_{4}$ paddlewheel units (e.g., $\mathrm{M}=\mathrm{Cu}^{2+}, \mathrm{Co}^{2+}$, and $\left.\mathrm{Zn}^{2+}\right){ }^{[141]}$ The graphitic structures consist of hydrophilic channels, in which the tert-butyl groups are connected through weak van der Waals interactions. It can be inferred from their structures that the hydrophobic cages should be the main storage space for gas molecules, while the hydrophilic channels should act as passages for gas molecules to enter the cages through the tert-butyl groups that serve as gates. The pore size can be modulated in a linear fashion by varying the temperature, giving rise to an infinite number of mesh sizes between 2.9 and $5.0 \AA$ (covering the range of most industrially important gas separations). ${ }^{[141]}$ As the temperature is raised, the amplitude of thermal vibration of the tert-butyl group also increases, leading to an aperture enlargement which permits $\mathrm{CO}_{2}$ and $\mathrm{N}_{2}$ to permeate, whilst blocking the relatively larger $\mathrm{CH}_{4}$ molecules. This selective adsorption has been observed under cryogenic conditions, however the development of MAMS for gas separations at ambient temperatures is being pursued. Strategies that are being considered in this context to tune the mesh sizes and the temperature-dependent properties include changing the functional groups of a linker, ${ }^{[142]}$ adjusting the length and bulkiness of the linkers, ${ }^{[141]}$ taking advantage of interpenetration, ${ }^{[143]}$ introducing coordinatively unsaturated metal centers, ${ }^{[114]}$ and making use of postsynthetic functionalization strategies. ${ }^{[144]}$ A recent review article ${ }^{[16]}$ provides a comprehensive summary of the materials and their ability for application in $\mathrm{CO}_{2}$ separation from $\mathrm{N}_{2}$, $\mathrm{CH}_{4}$, and $\mathrm{H}_{2}$ gases, amongst others.

\subsubsection{Surface-Functionalized Frameworks}

The grafting of functional groups with a high affinity for $\mathrm{CO}_{2}$ onto the surfaces of porous materials through ligand 
modification, or coordination to unsaturated metal centers has been employed as a strategy to enhance the capacity and selectivity for $\mathrm{CO}_{2}$ adsorption. This approach has analogies with other functionalized solid adsorbents such as aminegrafted silicas; however, the crystalline nature of metalorganic frameworks provides for a molecular level of control in tuning the gas separations properties.

Frameworks containing open metal sites have been selectively grafted with molecules that have a high affinity for $\mathrm{CO}_{2}$. For example, $\left[\mathrm{Zn}_{2}(\mathrm{bttb})\left(\mathrm{py}-\mathrm{CF}_{3}\right)_{2}\right]$ (where bttb ${ }^{4-}=$ $4,4^{\prime}, 4^{\prime \prime}, 4^{\prime \prime \prime}$-benzene-1,2,4,5-tetrayltetrabenzoate) incorporates the highly polar pyridine derivative py- $\mathrm{CF}_{3}$ (4-(trifluoromethyl)pyridine) shown in Figure $6 a^{[123]}$ While grafting reduces the surface area of the framework to $300 \mathrm{~m}^{2} \mathrm{~g}^{-1}$ relative to the non-functionalized form, $\left[\mathrm{Zn}_{2}(\mathrm{bttb})\right]\left(1370 \mathrm{~m}^{2} \mathrm{~g}^{-1}\right)$, functionalization leads to a remarkable enhancement in the $\mathrm{CO}_{2}$ uptake compared with $\mathrm{N}_{2}$ in the low pressure region (0-1 bar) relevant to flue gas separations. Indeed, the $\mathrm{CO}_{2} /$ $\mathrm{N}_{2}$ selectivities calculated from binary mixtures using IAST for the py- $\mathrm{CF}_{3}$ modified framework are higher than the experimental selectivities for zeolite $13 \mathrm{X}^{[51]}$ and activated carbon. ${ }^{[128]}$

In contrast to the number of reported frameworks possessing Lewis acid sites which originate from coordinatively unsaturated metal centers, Lewis base functionalized frameworks are seldom observed owing to the tendency of Lewis basic sites to coordinate metals during framework synthesis. The potential for enhanced $\mathrm{CO}_{2}$ adsorption due to acid-base interactions in the latter case led to the discovery of the sulfone-functionalized material $\left[\mathrm{H}_{3} \mathrm{O}\right]\left[\mathrm{Zn}_{7}\left(\mu_{3}-\mathrm{OH}\right)_{3^{-}}\right.$ (bbs) ${ }_{6}$ (UoC-1, bbsH $_{2}=4,4^{\prime}$-bibenzoic acid-2,2'-sulfone, Figure $6 \mathrm{~b}) .{ }^{[124]}$ The material exhibited reversible and selective $\mathrm{CO}_{2}$ adsorption over $\mathrm{CH}_{4}, \mathrm{~N}_{2}$ and $\mathrm{H}_{2}$ due to a preferential interaction between $\mathrm{CO}_{2}$ and the polar sulfone groups.

In view of the affinity of amines towards $\mathrm{CO}_{2}$, aminefunctionalized ligands have been incorporated into a number of frameworks in an attempt to enhance the selectivity and adsorption. An enhancement in the $\mathrm{CO}_{2}$ uptake relative to $\mathrm{CH}_{4}$ was observed for the flexible amino-MIL-53(Al) framework $\left[\mathrm{Al}(\mathrm{OH})\left(\mathrm{NH}_{2} \mathrm{bdc}\right)\right]$ compared with the parent MIL53(Al) framework. ${ }^{[25]}$ Pulse chromatographic measurements revealed a separation factor of 60 for the functionalized material at low surface coverage, compared with ca. 5 for the parent framework. The magnitude of the zero-coverage adsorption enthalpy for $\mathrm{CO}_{2}$ also increases from -20.1 to $-38.4 \mathrm{~kJ} \mathrm{~mol}^{-1}$ upon functionalization. The incorporation of dangling amino groups reduces the number of apolar sites relative to the parent framework, resulting in negligible $\mathrm{CH}_{4}$ adsorption at pressures below 2 bar in the former case. Clearly, the presence of amino and $\mathrm{OH}$ groups drastically enhances the selectivity of the framework towards $\mathrm{CO}_{2}$ adsorption. Similar enhancements have been reported in the amine-functionalized frameworks $\left[\mathrm{Ni}_{2}\left(\mathrm{NH}_{2} \mathrm{bdc}\right)_{2}(\mathrm{dabco})\right]$ $($ dabco $=1,4$-diazabicyclo[2.2.2]octane $)$ and $[\operatorname{In}(\mathrm{OH})$ $\left(\mathrm{NH}_{2}\right.$ bdc $)$, relative to their non-functionalized analogs. ${ }^{[26]}$

Alkylamine-functionalized frameworks have also been shown to enhance the selectivity for $\mathrm{CO}_{2}$ adsorption, especially at the low pressures relevant to flue gas separation. For example, the air- and water-stable framework $\mathrm{HCu}\left[\left(\mathrm{Cu}_{4} \mathrm{Cl}\right)_{3^{-}}\right.$

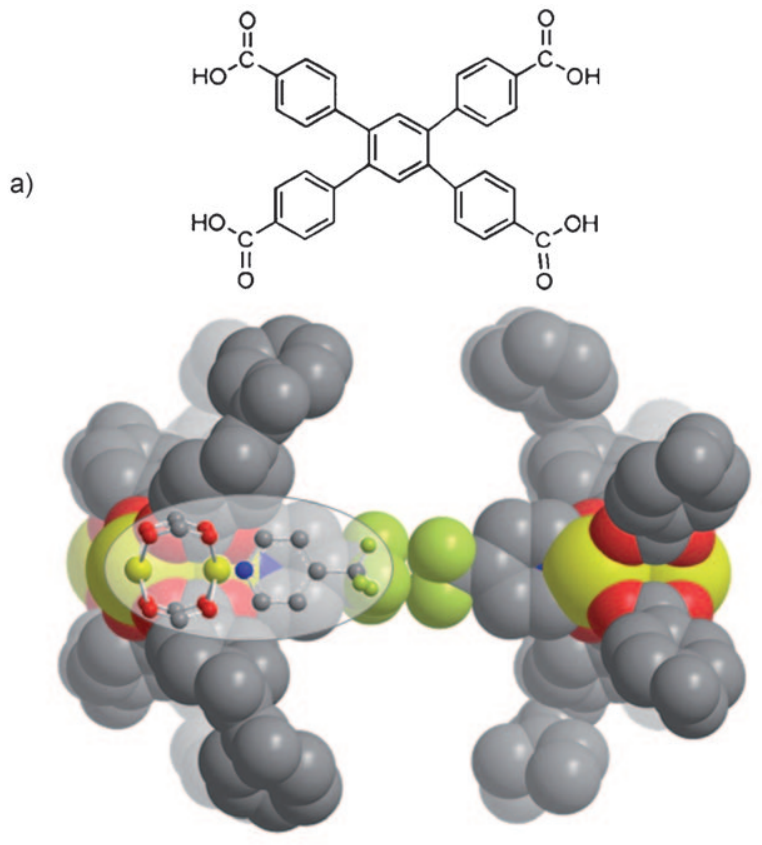

b)<smiles>O=C(O)c1ccc2c(c1)S(=O)(=O)c1cc(C(=O)O)ccc1-2</smiles>

c)

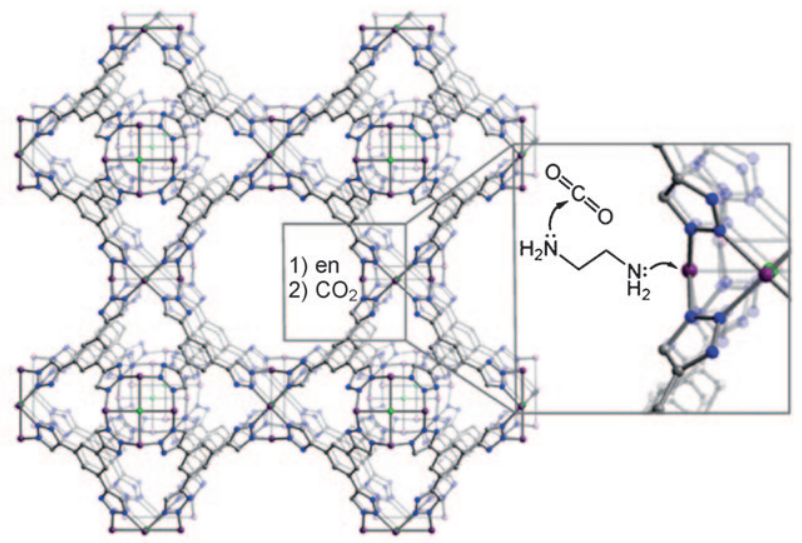

Figure 6. Examples of functionalized metal-organic frameworks. a) 4,4',4',4'"'-Benzene-1,2,4,5-tetrayltetrabenzoic acid and a portion of the framework $\left[\mathrm{Zn}_{2}(\mathrm{~L})\left(\mathrm{py}-\mathrm{CF}_{3}\right)_{2}\right]$ as a space-filling model, where $\mathrm{L}$ is the tetra-anionic form of the ligand. ${ }^{[123]}$ The inset shows the interaction between one of the py- $\mathrm{CF}_{3}$ ligands and a $\mathrm{Zn}_{2}$ cluster unit. Yellow, red, blue, and gray spheres represent $\mathrm{Zn}, \mathrm{O}, \mathrm{N}$, and $\mathrm{C}$ atoms, respectively. b) The ligand $4,4^{\prime}$-bibenzoic acid-2,2'-sulfone. ${ }^{[124]}$ c) A portion of the framework $\mathrm{HCu}\left[\left(\mathrm{Cu}_{4} \mathrm{Cl}\right)_{3}(\mathrm{BTTri})_{8}(\mathrm{en})_{5}\right]$ showing one of the en-functionalized $\mathrm{Cu}^{2+}$ sites and its interaction with a $\mathrm{CO}_{2}$ molecule. ${ }^{[127]}$ Purple, blue, green, and gray spheres represent $\mathrm{Cu}, \mathrm{Cl}, \mathrm{N}$, and $\mathrm{C}$ atoms, respectively. Non-framework $\mathrm{H}$ and $\mathrm{Cu}$ atoms, and hydrogen atoms are omitted for clarity.

(BTTri) $\left.{ }_{8}\right]\left(\mathrm{H}_{3} \mathrm{BTTri}=1,3,5\right.$-tri(1H-1,2,3-triazol-4-yl)benzene $)$ contains exposed metal sites which can be reacted postsynthetically with diamines such as ethylenediamine (en). ${ }^{[127]}$ As shown in Figure $6 \mathrm{c}$, one amine group in $\mathrm{HCu}\left[\left(\mathrm{Cu}_{4} \mathrm{Cl}\right)_{3^{-}}\right.$ $\left.(\mathrm{BTTri})_{8}(\mathrm{en})_{5}\right]$ is linked to a coordinatively unsaturated metal site, while the other is available for selective uptake 
of $\mathrm{CO}_{2}$. Despite a reduced surface area compared with the parent framework, the en-functionalized material exhibited a higher uptake of $\mathrm{CO}_{2}$ at very low pressures (up to 0.01 bar) compared with the non-grafted material, which gave rise to an initial enthalpy of adsorption at zero coverage of $-90 \mathrm{~kJ} \mathrm{~mol}^{-1}$ (compared with $-21 \mathrm{~kJ} \mathrm{~mol}^{-1}$ for the nongrafted material). This chemisorption interaction was the strongest reported to date in a framework material. There is a need to probe the mechanism of the alkylamine- $\mathrm{CO}_{2}$ chemisorption interactions in the presence and absence of water, to search for the formation of carbamate and/or hydrogen carbonate species (such as those shown in Scheme 1).

Clearly, extensive possibilities can be envisaged to tune the selectivity and heat of adsorption in amine-functionalized frameworks by incorporating secondary, tertiary or sterically hindered amines at open metal coordination sites, or on the bridging ligands. Such frameworks should overcome some limitations of other $\mathrm{CO}_{2}$ capture materials, most notably: 1) the structural ambiguities present in hyperbranched aminosilica materials produced by surface polymerization ${ }^{[57]}$ and 2) the lack of stability over multiple cycles for amineimpregnated silicas and zeolites. ${ }^{[54]}$

It is important to note that studies on the viability of metal-organic frameworks as $\mathrm{CO}_{2}$ capture materials under realistic industrial conditions have received relatively limited attention to date. While the high robustness and stability of zeolitic imidazolate frameworks has been established $\left[{ }^{[99]}\right.$ the majority of metal-organic frameworks exhibit comparatively lower stabilities, and their sensitivity to chemical degradation in the presence of air and water, as well as their sensitivity to other impurities in gas streams (see Table 1) poses a major impediment to their practical application. Ultimately, the integration of metal-organic frameworks into practical $\mathrm{CO}_{2}$ capture processes requires a serious assessment of their performance as membranes for gas separation, or in large adsorbent beds where pressure or temperature swing adsorption approaches may be employed. ${ }^{[8]}$ Relatively few experimental studies have probed the kinetics of gases diffusing in MOFs ${ }^{[145-149]}$ although a growing number of computational investigations have provided important insights. Low gas permeance could be a problem, in particular for MOFs with small, or dynamically restricted (in the case of MAMS) pore openings.

\subsubsection{Simulations of $\mathrm{CO}_{2}$ Capture in Metal-Organic Frameworks and Related Materials}

We have highlighted the most recent advances in new materials for $\mathrm{CO}_{2}$ capture. One of the most exciting aspects is the nearly infinite array of structures that can be prepared; however, it may be impossible, or at least very impractical to synthesize and test all of the conceivable structures. The development of computational techniques that can deal with this eruption of novel materials is critical, and must focus on: 1) describing the thermodynamic and transport properties accurately and 2) screening for optimal capture materials.

Molecular simulation is one of the most promising methods to predict the properties of the molecules adsorbed in the pores of microporous materials. In these simulations, one assumes that the interactions between the atoms can be described accurately using a (classical) force field. The force fields together with the crystal structure of the frameworks are used in molecular dynamics or Monte Carlo simulations to compute the thermodynamic and transport properties. ${ }^{[150]}$ For zeolites, these methods have been very successful in predicting the adsorption and diffusion properties of many different types of molecules, ${ }^{[151]}$ and recently these methods have been extended to study the adsorption of gases such as $\mathrm{CO}_{2}$ and $\mathrm{CH}_{4}$ in metal-organic and covalent-organic frameworks.

\subsubsection{Force Fields}

Compared to zeolites, the structures of metal-organic frameworks can be controlled to a much higher degree through variations in the type and nature of the organic linkers and the metal centers. From a computational perspective, it is important to describe the entire range of interactions between all atoms in a given system using force fields. These force fields have three components: one that describes the interactions between the atoms of the frameworks (or the other materials) as well as one that describes the interactions between the adsorbed gases, and the interactions between the adsorbed molecules and the atoms of the framework.

Computationally, it is very convenient to assume a rigid crystal structure for the framework. Indeed, if this assumption holds, there is no need for a force field describing the interactions between the atoms of the framework. For many systems, this assumption provides a reasonable description of the adsorption isotherms; however, there are several examples in which the structure of the material changes ${ }^{[152]}$ upon adsorption of, for example, water ${ }^{[153]}$ or carbon dioxide ${ }^{[119]}$ or by changing the temperature. ${ }^{[154]}$ Including framework flexibility slows the computations by one to two orders of magnitude. Recently, some progress has been made on the development of force fields and methods which describe structural changes in the materials. ${ }^{[135,155-158]}$

If the structure of a given framework is known, accurate force fields which describe the gas-gas and gas-framework interactions must be obtained. The gas-gas interactions are usually optimized to give an accurate description of the vapor-liquid coexistence properties, ${ }^{[159,160]}$ which provides a very sensitive test for the accuracy of these force fields. ${ }^{[161]}$ The gas-framework interactions pose a significantly greater challenge to obtain accurately. The typical force fields describing the interactions include dispersive interaction and Coulomb interactions. Polarization is also an important contribution; ${ }^{[162]}$ however, its inclusion raises the expense of the calculations and most studies include the effect indirectly through the introduction of effective parameters for the Coulomb and dispersive interactions. The parameters of these potentials are either fitted to experimental data or to quantum calculations. ${ }^{[137,163]}$ In the case of $\left[\mathrm{Zn}_{4} \mathrm{O}(\mathrm{bdc})_{3}\right]$, for example, a computational model which included both Lennard-Jones and Coulombic interactions was found to be essential to adequately model the adsorption behavior. ${ }^{[91]}$

Both approaches have serious shortcomings. Experimental data can be fit very accurately for one given system, but 
this does not guarantee that the potentials can be transferred to other systems. Meanwhile, quantum calculations suffer from the fact that both the dispersive interactions ${ }^{[164]}$ as well as charge distribution ${ }^{[135]}$ are very difficult to obtain, and different quantum methods give remarkably different results. ${ }^{[160]}$ Despite these limitations, many of the calculations performed to date provide a very reasonable description of the experimental adsorption isotherms. ${ }^{[165]}$

\subsubsection{Simulation of the Adsorption and Diffusion}

Here, we focus on those simulations that relate specifically to $\mathrm{CO}_{2}$ capture and for more general reviews we refer the reader to some excellent literature articles. ${ }^{[166,167]}$ A significant fraction of the computational work has been directed towards the validation of the force fields. ${ }^{[160,165]}$ The focus of most studies is on pure component data, as for these systems experimental data are available to test the force fields. ${ }^{[167]}$

Often the pure component isotherms exhibit steps, of which developing a better understanding will lead to improved force fields. For frameworks, flexibility is an essential factor in understanding these steps, ${ }^{[119,168]}$ however, this is not the only contribution. For example, the step in the adsorption isotherm of $\mathrm{CO}_{2}$ in MOF-177 has been explained in terms of a condensation of $\mathrm{CO}_{2}$ in the pores of the materials. ${ }^{[88,91]}$ The simulations showed excellent agreement with the experimental data using a rigid framework. A stepped isotherm for $\mathrm{CO}_{2}$ adsorption was also predicted in the rigid covalent-organic frameworks COF-8 and COF-12. ${ }^{[169]}$ Different materials including zeolites, metal-organic and covalent-organic frameworks have also been screened for their maximum adsorption capacities for $\mathrm{CO}_{2} \cdot{ }^{[65,170]} \mathrm{An}$ extensive series of Monte Carlo simulations on zeolites, metal-organic frameworks and covalent-organic frameworks has shown that stepped isotherms arise from cluster formation of guest molecules such as $\mathrm{CO}_{2}, \mathrm{CH}_{4}$ and Ar below a critical temperature. ${ }^{[171]}$ In particular, molecular cluster phenomena strongly influence the adsorption and diffusion characteristics of porous materials with pore sizes larger than $0.75 \mathrm{~nm}$, and this strategy may have considerable potential for enhancing the $\mathrm{CO}_{2} / \mathrm{CH}_{4}$ separation selectivities. ${ }^{[172]}$

An important application of molecular simulation is to screen materials for their optimal separation selectivity. ${ }^{[2,173]}$ The extension of pure component data to gas mixtures is relatively straightforward, and has led to many predictions of separation selectivities. ${ }^{[165,174,175]}$ Unfortunately, experimental data are lacking for most of these studies, and it is difficult to assess directly the reliability of the predictions. From our experience with the adsorption of hydrocarbons, it appears that once the pure component isotherms are accurately described, the molecular simulations provide a very reasonable prediction for the mixture isotherms. ${ }^{[151]}$

A very high selectivity towards $\mathrm{CO}_{2}$ was predicted in zeolite-like metal-organic frameworks that possess the RHO structure and contain $\mathrm{Na}^{+}$ions. ${ }^{[66]}$ The effect of substitution of the linker molecules has also been probed using quantum calculations, and showed that a careful design of the linker can tune the interactions with $\mathrm{CO}_{2} \cdot{ }^{[163]}$ For example, substitution of benzene molecules with halogens (e.g., tetrafluoro-, chloro-, bromo-, and dibromobenzene) leads to weaker interactions with $\mathrm{CO}_{2}$, while methyl substituents (such as mono-, di-, and tetramethylbenzene) enhance these interactions.

While most studies have been focused on $\mathrm{CO}_{2} / \mathrm{N}_{2}$ mixtures, the influence of water on the capacity and selectivity has also been considered. ${ }^{[108]}$ One would expect that water would compete with $\mathrm{CO}_{2}$ for the "most attractive" sites, thereby reducing both the selectivity and capacity. The simulations, however, showed that water molecules coordinated to open metal sites in $\left[\mathrm{Cu}_{3}(\mathrm{btc})_{2}\right]$ significantly increase $\mathrm{CO}_{2}$ adsorption. This effect has subsequently been experimentally confirmed. ${ }^{[108]}$

Clearly, there is tremendous scope for developments in computational methods for screening $\mathrm{CO}_{2}$ capture in framework materials. ${ }^{[173]}$ A significant and growing research effort is also underway on the incorporation of frameworks into membranes, and the simulation of the permeation selectivities for such hybrid systems.

The first information on the performance of frameworks as membranes for gas separations was obtained from a case study on the separation of $\mathrm{CO}_{2} / \mathrm{N}_{2}{ }^{[176-178]}$ and $\mathrm{CO}_{2} / \mathrm{CH}_{4}{ }^{[177]}$ mixtures by a hypothetical membrane consisting of $\left[\mathrm{Zn}_{4} \mathrm{O}\right.$ $(\mathrm{bdc})_{3}$ ] crystals. In addition to the importance of considering both the adsorption and diffusion of gas molecules, binary (rather than single component) adsorption isotherms were found to be crucial in order to adequately predict membrane performance in practical applications. IAST theory was employed to calculate the binary adsorption isotherms for an equimolar $\mathrm{CO}_{2} / \mathrm{CH}_{4}$ mixture, and on this basis, the adsorption selectivity was found to strongly favor $\mathrm{CO}_{2}$ over $\mathrm{CH}_{4}$.

These simulations were subsequently extended to examine the performance of $\left[\mathrm{Cu}_{3}(\mathrm{btc})_{2}\right]$ membranes for $\mathrm{CO}_{2} / \mathrm{CH}_{4}$ and $\mathrm{CO}_{2} / \mathrm{H}_{2}$ separations. ${ }^{[179]} \mathrm{A}$ comparison of the ideal selectivities (calculated from single gas adsorption isotherms) with the mixture selectivity demonstrated that the values differ significantly due to multi-component effects in the diffusing mixtures. The strongly adsorbing component (i.e., $\mathrm{CO}_{2}$ in a $\mathrm{CO}_{2} / \mathrm{H}_{2}$ mixture) reduces both the concentration gradient across the membrane for the weakly adsorbed component and the diffusion rate of the more mobile species (i.e., $\mathrm{H}_{2}$ ). The results indicate that the selection of frameworks for membrane-based gas separations must focus on both the adsorption and diffusion selectivities of the material. ${ }^{[24,179]}$

Such simulations are idealized in the sense that they describe membranes that are constructed from defect-free crystalline materials. Considering the very large number of different frameworks that could be employed to construct a membrane, and the time required for experimental measurements using gas mixtures under a range of conditions, computational simulations may prove to be critical in determining the most promising structures.

\subsection{Membranes}

Membrane separation technologies are projected to attain a high efficiency for $\mathrm{CO}_{2}$ capture owing to their selective 
extraction of $\mathrm{CO}_{2}$ from mixed gas streams, their low energy requirements and the flexibility in their possible configurations in industrial plants relative to conventional amine absorber/desorber columns. ${ }^{[18]}$ The constituent materials are typically classified as: inorganic (ceramic, metal oxide, metallic, molecular sieves, thin layer of $\mathrm{Pd}$ on ceramic or porous alumina cylinder as support, metal-organic frameworks) or organic (cellulose acetate, polymers such as polysulfone, polyamide, polyimide, cross-linked polydimethylphenyleneoxide, hollow fibers with high surface area to volume ratios of $1500-2000 \mathrm{~m}^{2} \mathrm{~m}^{-3}$ ).

A number of mechanisms for membrane separation have been identified, with the most important being solution diffusion and molecular sieving. ${ }^{[180]}$ These factors are formally defined by the gas permeability (transport factor) and selectivity (separation factor), respectively, and are inversely related. This trade-off is widely characterized graphically in a "Robeson Plot", ${ }^{[181]}$ from which an upper bound to membrane performance is observed. The goal of membrane studies has thus been to reach this maximum to achieve both high permeability and high selectivity, in addition to adequate robustness and material lifetime.

Inorganic membranes are comprised of either porous or non-porous materials, and have the advantage of a high temperature operation which is relevant for precombustion separation. ${ }^{[180,182]}$ Hydrogen transport membranes for precombustion separation allow one-step reforming, or a single intermediate water-gas shift reaction, and thus permit simultaneous hydrogen separation (the permeate) and $\mathrm{CO}_{2}$ capture. Since the retentate consists of a concentrated, highpressure $\mathrm{CO}_{2}$ stream, the compression energy for transport and storage is reduced. Hydrogen transport membranes are often based on microporous inorganic materials including zeolites, palladium alloy tubes, or ceramics such as inorganic perovskite oxides. $^{[183]}$

The mechanisms for separation in inorganic membranes are typically based upon adsorption selectivity and surface diffusion, which give rise to relatively low separation factors (e.g., $\mathrm{H}_{2} / \mathrm{CO}_{2}$ separation factor of 15 ). Commercially available $\gamma$-alumina and silica microporous membranes exhibit significantly higher separation factors (up to 40), however, these are dependent on the stability of the membrane pore size, which is adversely affected by steam in the feed streams. Dense ceramic membranes based on inorganic perovskite oxides (also known as proton conducting membranes) require high operational temperatures to achieve practical hydrogen flux rates (above $800^{\circ} \mathrm{C}$ ). Molecular sieves such as zeolites (aluminosilicate compositions) or non-zeolites (aluminophosphates and silica) have also been considered as inorganic membranes. In these cases, the separations are based on kinetic size discrimination within the channels of the porous structures.

Palladium-based composite membranes have been used for precombustion applications and are known for their high hydrogen selectivity and permeability over other gases in the temperature range $300-600^{\circ} \mathrm{C}$. Whilst palladium alloy tubes have been available for several decades, they are deemed too expensive for CCS applications due to the substantial thickness of the membrane which is required to achieve structural stability and high hydrogen flux rates. Indeed, a common disadvantage of a number of the aforementioned membranes is their lack of stability under the reforming environment present in processing plants (which contains steam and hydrogen sulfide).

Inorganic membranes, including Zeolite T, DDR, silicate1 and SAPO-34, have also been investigated for high pressure natural gas sweetening, and can exhibit high $\mathrm{CO}_{2} / \mathrm{CH}_{4}$ selectivities due to a combination of differences in diffusivity and competitive adsorption. ${ }^{[184]}$ Further improvements in the selectivity for SAPO-34, for example, were achieved by synthesizing the material on porous stainless steel tubes, or on $\alpha-\mathrm{Al}_{2} \mathrm{O}_{3}$ porous supports. In the latter case, a $\mathrm{CO}_{2} / \mathrm{CH}_{4}$ separation selectivity higher than 170 at $295 \mathrm{~K}$ and a feed pressure of $2.2 \mathrm{~atm}$ was achieved, and effective separation could still be observed up to $16.7 \mathrm{~atm}^{[184]}$

To provide an additional level of selectivity beyond that which may be obtained solely from a molecular sieving effect in inorganic membranes, hybrid membrane/chemical absorption processes have been considered for low pressure flue gas separations. Since the gas separation mechanism through a pure porous support is based mainly on size differences of the permeating molecules, the covalent functionalization of the pore walls has been suggested as a strategy to increase the $\mathrm{CO}_{2}$ selectivity. Examples include inorganic membranes such as zeolites, or a ceramic support such as $\mathrm{Al}_{2} \mathrm{O}_{3}$, onto which a porous separating layer such as silica, alumina or zirconia is attached, followed by a functional layer such as $\mathrm{MgO}$ which has a high chemical affinity for $\mathrm{CO}_{2} \cdot \mathrm{CO}_{2} / \mathrm{N}_{2}$ selectivities as high as 120 at $350^{\circ} \mathrm{C}$ have been reported (a value which approaches Robeson's upper bound). ${ }^{[180]}$ Hybrid membranes are advantageous in the respect that their degradation is minimized through the prevention of oxygen contact with the absorbent.

Membranes consisting of metal-organic frameworks immobilized in various supports also show exciting prospects for gas separations. A $\left[\mathrm{Cu}_{3}(\mathrm{btc})_{2}\right]$ membrane has been prepared on a copper net, ${ }^{[185]}$ and porous alumina substrates have been used as supports for $\left[\mathrm{Zn}_{4} \mathrm{O}(\mathrm{bdc})_{3}\right]^{[186]}$ and $[\mathrm{Zn}$ (bim) $)_{2}$ (ZIF-7, bim $^{-}=$benzimidazolate). ${ }^{[187]}$ In the latter case, the membrane exhibited an exceptional $\mathrm{H}_{2} / \mathrm{CO}_{2}$ separation ability, as well as air, water and thermal stability (up to $500^{\circ} \mathrm{C}$ ). Computational simulation is proving to be an invaluable technique to screen the performance of metalorganic frameworks for membrane separations applications. These are relatively more difficult than simulations for adsorption isotherms, among other reasons because the flexibility of the framework should be taken into account.

Inorganic ion transport membranes have been proposed for the separation of oxygen from gas mixtures as a potentially more viable alternative to cryogenic oxygen removal in oxyfuel combustion processes, for example. ${ }^{[35]}$ The membrane itself uses conductors which are composed of mixed-metal oxides at high excitation temperatures of 800 $900^{\circ} \mathrm{C}$ for both electron and oxygen ion conductivity. Such membranes are currently being investigated as part of Zero Emission Power Plant projects, since they enable inherent $\mathrm{CO}_{2}$ capture directly in the combustion chamber of the gas turbine. A major advantage is that the process is driven by the 
permanent withdrawal of oxygen on the permeate side as a consequence of combustion.

Polymeric membranes constitute a second major class which are widely employed commercially for natural gas sweetening $\left(\mathrm{CO}_{2} / \mathrm{CH}_{4}\right.$ separation). ${ }^{[180]}$ They are typically based on cellulose acetate and derivatives thereof, whose structures are tailored by varying the glass transition temperature. These polymers are highly susceptible to degradation through plasticization and compaction under feed stream conditions, and are not deemed to be viable for flue gas applications. Polysulfone and polyimide polymer-based membranes are amongst the most widely reported membranes in the patent literature. They exhibit excellent advantages over cellulose acetate membranes, including improved permeabilities and selectivities as well as thermal, chemical and placticization resistance. ${ }^{[180]}$ Recently, a new class of microporous polymeric structures known as polymers of intrinsic microporosity have been reported. ${ }^{[188]}$ These materials are comprised of randomly contorted rod-like structures which form intrinsic cavities within the membrane, and thus exhibit high free volumes and higher gas solubilities compared with conventional molecular sieves. Given that a number of extensive review articles detailing the advantages of polymeric membranes have appeared in recent years, ${ }^{[14,18,180,189,190]}$ we focus here instead on emerging concepts in the field of polymer-based membrane materials.

Membrane selectivity currently depends on the relative sizes of gas molecules and the relative condensability of the gas molecules. From this perspective, two major challenges exist in order for polymeric membranes to become a viable route for gas separation. Firstly, the membranes must possess relatively small pore sizes to selectively separate the gas molecules of interest. Novel types of assemblies (known as a functionalized polymeric composite membranes) have thus been proposed, and consist of a base porous support and a thin layer of permselective materials (typically $0.2-1 \mu \mathrm{m}$ thick). ${ }^{[191]}$ Although nanoporous polymer thin films can be routinely prepared, the ability to obtain porous films with sub-nanometer features remains a significant challenge. Secondly, due to the limited heterogeneity of polymers, the spatial arrangement of each individual monomer cannot be specifically controlled. Fine-tuning the interactions between the gases and polymeric membranes is required to increase the selectivity between similarly sized molecules.

Hypercrosslinked networks hold great promise as new materials for polymer membranes. Such networks are comprised of aromatic rings which are connected through linking groups of well-defined lengths to form a porous framework. Modification of the network surface could be achieved through functionalization of the precursor polymer and/or the hypercrosslinked layer. ${ }^{[192]}$ The validity of this concept has already been demonstrated by the development of hydrogen storage materials ${ }^{[192-194]}$ based on hypercrosslinked polyaniline, which was synthesized by reaction of the linear polyaniline precursor with a difunctional reagent such as diiodobenzene. ${ }^{[195]}$ A number of other precursor materials could be explored to tune the pore sizes and polarities. A similar concept has been employed to produce $\mathrm{CO}_{2}$ selective polymeric membranes containing amines in crosslinked polyvinyl alcohol. ${ }^{[196]}$

Further possibilities for novel polymer membranes involve the creation of hybrid assemblies. For example, the combination of cyclopeptides and synthetic polymers could be used to generate hybrid biomolecular materials which may provide ideal internal structures for gas separation. Mixedmatrix membranes have also recently been considered, by combining the advantageous features of inorganic and polymeric membranes in an effort to overcome the limitations of each class. ${ }^{[180]}$ Such membranes are characterized by a hetereogeneous gas separation layer comprising discrete inorganic particles dispersed in a continuous polymeric phase. For example, metal-organic frameworks such as $\left[\mathrm{Cu}(\right.$ bpy $\left.)\left(\mathrm{SiF}_{6}\right)\right]$ have been incorporated into Matrimid polymers to form free standing mixed-matrix membranes for $\mathrm{CO}_{2} /$ $\mathrm{CH}_{4}$ separations. ${ }^{[197]}$ AMH-3/PBI membranes which consist of a nanocomposite of the layered silicate AMH-3 and polybenzimidazole (PBI) have also been prepared, and exhibit $\mathrm{H}_{2}$ / $\mathrm{CO}_{2}$ selectivities that are doubled compared with the polymer itself. $^{[198]}$

Facilitated liquid membranes constitute another important class of materials which incorporate a number of liquid absorption stages to achieve $\mathrm{CO}_{2}$ separation from flue gas streams. ${ }^{[183]}$ The separations are facilitated by preferential reversible chemical reactions between $\mathrm{CO}_{2}$ and "carriers" such as carbonates, amines and molten salt hydrates, ${ }^{[199]}$ carbonic anhydrase or ionic liquids ${ }^{[200]}$ which are dissolved in the porous membrane. For example, facilitated transport ionic liquid membranes which consist of an amine-functionalized ionic liquid encapsulated in a polymeric support (such as polysulfones or cross-linked Nylon 66) exhibit exceptionally high $\mathrm{CO}_{2} / \mathrm{H}_{2}$ selectivities (ca. 10). ${ }^{[201,202]}$ The cross-membrane transport is driven by the difference in the partial pressure of $\mathrm{CO}_{2}$ across the membrane ${ }^{[183]}$ which is higher on the side that contacts the flue gas than on the other. This pressure gradient can be obtained by pressurizing the gas on one side of the membrane, and/or applying a vacuum on the other. Significantly, the pressure differential supplies the energy for separation and is the key to the low energy penalty of the process.

Clearly, membranes represent a promising technology for gas separation, however, they suffer a number of drawbacks, particularly with regard to $\mathrm{CO}_{2}$ capture from flue gas. In this case, the low $\mathrm{CO}_{2}$ partial pressure provides a minimal driving force for gas separation, which creates an energy penalty due to the need for compression of the feed gas. ${ }^{[203]}$ Membrane materials also suffer from a decrease in permeability over time due to particulate deposition on the surface.

\section{4. $\mathrm{CO}_{2}$ Fixation: Mineralization, Fuels, and Biofixation}

Chemical fixation through the conversion of $\mathrm{CO}_{2}$ into fuels, commodity chemicals, construction materials, or mineral carbonates represents another promising alternative for $\mathrm{CO}_{2}$ capture which has been described in detail in a recent article. ${ }^{[19]}$ The challenge here lies in the fact that $\mathrm{CO}_{2}$ is a highly stable compound containing a low amount of chemical 
energy, such that natural conversion processes may be slow and inefficient as a result.

A recently disclosed method for direct mineralization involves the production of cement through the reaction of $\mathrm{CO}_{2}$ in flue gas with calcium and magnesium in seawater. ${ }^{[8]}$ The process claims to react 0.5 tons of $\mathrm{CO}_{2}$ per ton of cement produced, which compares with one ton of $\mathrm{CO}_{2}$ for each ton of cement produced using current processes.

$\mathrm{CO}_{2}$ may also be used to produce fuels such as methanol, formic acid, dimethyl carbonate, methyl formate and higher hydrocarbons, as well as polymeric materials and pharmaceutical chemicals. ${ }^{[19]}$ Given the sheer magnitude of $\mathrm{CO}_{2}$ emissions and the need for effective catalysts, however, it appears unlikely that this approach will make a major contribution towards reducing $\mathrm{CO}_{2}$ emissions in the nearterm.

A "sunshine to petrol" approach has recently been proposed, by harnessing photosynthetic energy to recycle $\mathrm{CO}_{2}$ into biofuels by mimicking the natural processes of photosynthesis. $^{[204]}$ This biological fixation method uses microalgae (microscopic aquatic plants that carry out photosynthesis) to produce renewable transportation fuels, while also removing $\mathrm{CO}_{2}$ from large point sources using either open ponds or enclosed systems such as photobioreactors. Photosynthetic $\mathrm{CO}_{2}$ mitigation is advantageous in that it does not require pure $\mathrm{CO}_{2}$, and does not incur costs for separation, capture and compression of $\mathrm{CO}_{2}$ gas.

\subsection{Other Promising Capture Technologies}

The final category of carbon capture technologies considered here comprises novel concepts based on techniques at the pilot or laboratory stage of development. Processes that use chemical looping, or hydration to separate $\mathrm{CO}_{2}$ are examples of such technologies.

A new approach for $\mathrm{CO}_{2}$ capture involves clathrate or gas hydrate crystallization and is applicable to both post- and precombustion capture from flue gas or synthesis gas, respectively. ${ }^{[205,206]}$ The process relies on the ability of water to form non-stoichiometric crystalline compounds in the presence of $\mathrm{CO}_{2}, \mathrm{~N}_{2}, \mathrm{O}_{2}$ and $\mathrm{H}_{2}$, as well as natural gas components at high pressures (10-70 atm) and low temperatures $\left(\right.$ near $0^{\circ} \mathrm{C}$ ). The gas molecules are occluded within a network of cavities which are formed by a hydrogen bonded network of water molecules. A $\mathrm{CO}_{2} / \mathrm{N}_{2}$ or $\mathrm{CO}_{2} / \mathrm{H}_{2}$ mixture contacts water at a suitable temperature and pressure to form hydrate crystals, which are separated and decomposed to create a $\mathrm{CO}_{2}$-rich stream. The preferential incorporation of $\mathrm{CO}_{2}$ over the other gases into the hydrate crystal phase arises from the difference between the hydrate formation pressure for $\mathrm{CO}_{2}$ relative to $\mathrm{N}_{2}$ or $\mathrm{H}_{2}$.

The high pressure and low temperature requirements for $\mathrm{CO}_{2}$ capture through hydrate formation impose significant challenges for the implementation of the technology. ${ }^{[14]}$ Hybrid separations processes, which combine the advantages of hydrate crystallization with membrane technologies have thus been proposed for high pressure $\mathrm{CO}_{2} / \mathrm{H}_{2}$ separations relevant to IGCC plants. ${ }^{[207]}$ Such membrane-based processes have the potential to be less energy intensive and voluminous than absorption processes. Interestingly, the use of additives including tetrahydrofuran or propane has also been shown to lower the equilibrium pressure required for hydrate formation from $\mathrm{CO}_{2} / \mathrm{H}_{2}$ mixtures, without affecting the kinetics and separation efficiency. ${ }^{[206]}$

In chemical looping combustion the combustion step is separated into oxidation and reduction reactions, and a transition metal oxide (e.g., of $\mathrm{Mn}, \mathrm{Fe}, \mathrm{Co}$, or $\mathrm{Ni}$ ) is employed as an oxygen carrier to circulate between the two reactors. ${ }^{[12,46]}$ The oxide particles react with a fuel in a fluidized bed reactor, producing solid metal particles and a mixture of $\mathrm{CO}_{2}$ and $\mathrm{H}_{2} \mathrm{O}$. The reduced metal oxide is subsequently transferred to an air reactor where the metal is oxidized. The outlet gas in this case consists of nitrogen and a reduced amount of oxygen. The net chemical reaction for the two reactors is identical to that for normal combustion, with the advantage that the $\mathrm{CO}_{2}$ is essentially pure after its separation from water. No additional energy demands or costly external equipment are therefore required for capture.

\section{Future Prospects}

Clearly, no unique solution exists currently to solve the problem of $\mathrm{CO}_{2}$ capture, and this complex challenge will almost certainly require the integration of several technology options. This review article has sought to highlight the challenges for $\mathrm{CO}_{2}$ separation methods which have the greatest likelihood of reducing $\mathrm{CO}_{2}$ emissions to the atmosphere, namely postcombustion (low pressure, predominantly $\mathrm{CO}_{2} / \mathrm{N}_{2}$ separation), precombustion (high pressure, predominantly $\mathrm{CO}_{2} / \mathrm{H}_{2}$ separation) capture and natural gas sweetening (predominantly $\mathrm{CO}_{2} / \mathrm{CH}_{4}$ separation). Importantly, the requirements for capture materials vary beyond those discussed here depending on the specific technology and stage in a particular process at which $\mathrm{CO}_{2}$ capture occurs. For example, the selectivity may be critical in some applications, but less so in others, tolerance to other components in the gas stream such as water and $\mathrm{H}_{2} \mathrm{~S}$ may or may not be required, and the long term chemical and mechanical stability may be more or less important.

While improvements to industrial processes and reductions in the plant footprints will make some contribution to the capture problem, the key factor which underlies significant advancements lies in improved materials that perform the separations. The results of research efforts in this area will have widespread implications not just for $\mathrm{CO}_{2}$ sequestration, but other gas separations, as well as solar-to-fuels conversions, $\mathrm{H}_{2}$ production, etc. Although outside the scope of the present article, the direct capture of $\mathrm{CO}_{2}$ from ambient air represents another emerging technology option deserving of further research effort. ${ }^{[25]}$

The production of hybrid materials also holds great promise. For example, metal-organic frameworks could be closely integrated with hydrophobic polymers to produce block co-polymers which prohibit the permeation of water. Serious advantages over fixed-bed adsorption methods are also expected for the application of metal-organic frame- 
works to gas separations if reliable methods can be developed for integrating these free-flowing powder materials into membranes. ${ }^{[14]}$

With respect to new materials, the key scientific challenges are the development of a level of molecular control, and the development of modern characterization and computational methods that will support, guide and provide further refinement to the most promising structures. Characterization of these new materials at the molecular level is essential. To accelerate the process, high-throughput characterization should be employed in cases where high-throughput materials synthesis is possible.

For crystalline materials, measurements of the adsorption isotherms and breakthrough curves will be essential, while for polymeric materials, the focus should be on adsorption and permeation experiments on small polymer films. In combination with gas uptake measurements on powders or films, the structural information should allow issues regarding the loading of potential separation materials with different gases to be addressed. A parameter that must be assessed in all cases is the enthalpy of adsorption, since the cost for regeneration of any capture material is critically dependent on the energy required to remove the $\mathrm{CO}_{2}$.

The static properties of the gas-loaded materials could be assessed using in-situ techniques such as resonant X-ray absorption spectroscopy, which has the capability to study interactions between gas molecules and the matrix in a spatially averaging manner. For crystalline materials, in-situ single crystal X-ray diffraction can be employed to determine the material structure under different loading conditions. Chemical information on polymer thin films could be obtained at the spatial resolution of a few nanometers using energy-dispersive spectroscopy and through surface area NMR relaxometry methods.

Characterization of the molecular transport properties of the materials is essential in order to obtain a molecular understanding of transport processes. Important fundamental questions include: how the structure changes with loading, how adsorbates bind to the material, and if so where and through which interaction, as well as how different permeates influence each other's solubility.

Techniques such as resonant soft X-ray spectroscopy to study the internal chemistry of gas permeates and separation media, and solid-state NMR may prove of great utility in relating diffusion to molecular structure. The most significant conclusion from the measurements will be the ability to correlate microscopic absorbate dynamics with the structural information on loaded materials. A comparison between of the microscopic mobility and the macroscopic diffusion should provide insights into the mechanism of selective transport through these materials.

In parallel with experimental studies, computational modeling methods must be further developed as a tool to predict the performance of materials or membranes which are proposed for a given separation process. Such techniques will enable large scale screening of new materials. Ultimately, a clear understanding of the structure-function relationships will direct experimental efforts towards a new generation of materials with improved $\mathrm{CO}_{2}$ capture abilities. The modeling of transport and adsorption properties for crystalline materials is a less complex issue than that for amorphous polymer membranes. ${ }^{[151,208]}$ Hence, developing molecular models and force fields based on the detailed structures is a prerequisite for the successful prediction of thermodynamic and transport properties of new materials.

Clearly, the combination of material synthesis, characterization, and computation requires a significant critical mass of expertise of a scope only afforded through extensive scientific collaborations. Furthermore, scientists and engineers must address the question of how the most promising materials will perform in an actual separation process. Beyond these considerations, the engineering economics of the new materials must be evaluated upon scaling-up the materials for industrial applications, and economic models must be established to cover lifecycle $\mathrm{CO}_{2}$ separation, capture and sequestration costs for various technologies. The ease and cost of large scale synthesis of membrane materials and metalorganic frameworks for example, will be critical in determining their applicability on an industrial scale. While a detailed analysis of these issues was outside the scope of the present review, this aspect demands serious attention from researchers in the field.

While no fully integrated, commercial-scale CCS projects are in operation to date, many of the component technologies for the compression and transportation (e.g., through preexisting pipelines for instance) of $\mathrm{CO}_{2}$ are relatively mature. Progress has clearly been made on the preparation and testing (at the pilot plant stage) of new materials for capture, however, there is an urgent need to develop new concepts and to accelerate the deployment of cost-effective materials to the market. The long term storage of $\mathrm{CO}_{2}$ is the subject of a number of major pilot projects worldwide, and is envisaged in deep geological formations such as saline aquifers or depleted oil/gas fields, by injection into oceans, or by sequestration in the form of mineral carbonates.

Despite the numerous challenges surrounding $\mathrm{CO}_{2}$ capture, and the various political, regulatory and economic drivers which will ultimately dictate the time-to-deployment for new CCS schemes, the time is ripe for us as a scientific community to play a central role in solving the $\mathrm{CO}_{2}$ capture problem.

This work was supported by the Sustainable Products \& Solutions Program at the University of California, Berkeley. We thank the 1851 Royal Commission and the AmericanAustralian Association for Research Fellowships for support of D.M.D. B.S. and J.R.L. were supported as part of the Center for Gas Separations Relevant to Clean Energy Technologies, an Energy Frontier Research Center funded by the U.S. Department of Energy, Office of Science, Office of Basic Energy Sciences under Award Number DE-SC0001015.

Received: January 25, 2010

Published online: July 22, 2010

[1] N. Stern, Stern Review on the Economics of Climate Change, Cambridge University Press, Cambridge, 2006. 
[2] B. Metz, O. Davidson, H. de Coninck, M. Loos, L. Meyer, Intergovernmental Panel on Climate Change. Special Report on Carbon Dioxide Capture and Storage, Cambridge University Press, Cambridge, 2005, http://www.ipcc.ch/.

[3] M. Z. Jacobson, Energy Environ. Sci. 2009, 2, 148.

[4] United Nations Framework Convention on Climate Change, http://unfccc.int/2860.php.

[5] McKinsey Climate Change Initiative, Carbon Capture \& Storage: Assessing the Economics, McKinsey \& Company, 2008.

[6] G. T. Rochelle, Science 2009, 325, 1652.

[7] IPCC, IPCC Special Report on Carbon Dioxide Capture and Storage, Cambridge University Press, Cambridge, 2005.

[8] Electric Power Research Institute, Program on Technology Innovation: Post-combustion $\mathrm{CO}_{2}$ Capture Technology Development, Electric Power Research Institute, Palo Alto, 2008.

[9] R. S. Haszeldine, Science 2009, 325, 1647.

[10] Science 2009, 325, 1644.

[11] The National Mining Association of the American Mining Industry, Status of CCS Development, http://www.nma.org/ccs/ ccsprojects.asp.

[12] J. D. Figueroa, T. Fout, S. Plasynski, H. McIlvried, R. D. Srivastava, Int. J. Greenhouse Gas Control 2008, 2, 9.

[13] S. Choi, J. H. Drese, C. W. Jones, ChemSusChem 2009, $2,796$.

[14] D. Aaron, C. Tsouris, Sep. Sci. Technol. 2005, 40, 321.

[15] M. P. Suh, Y. E. Cheon, E. Y. Lee, Coord. Chem. Rev. 2008, 252, 1007.

[16] J.-R. Li, R. J. Kuppler, H.-C. Zhou, Chem. Soc. Rev. 2009, 38, 1477.

[17] R. E. Morris, P. S. Wheatley, Angew. Chem. 2008, 120, 5044; Angew. Chem. Int. Ed. 2008, 47, 4966.

[18] A. D. Ebner, J. A. Ritter, Sep. Sci. Technol. 2009, 44, 1273.

[19] K. M. K. Yu, I. Curcic, J. Gabriel, S. C. E. Tsang, ChemSusChem 2008, 1, 893.

[20] M. Radosz, X. Hu, K. Krutkramelis, Y. Shen, Ind. Eng. Chem. Res. 2008, 47, 3783.

[21] Z. Yong, V. Mata, A. E. Rodrigues, Sep. Purif. Technol. 2002, $26,195$.

[22] M. C. Trachtenberg, R. M. Cowan, D. A. Smith in Proceedings of the Sixth Annual Conference on Carbon Capture \& Sequestration, Pittsburgh, 2007.

[23] P. Chowdhury, C. Bikkina, S. Gumma, J. Phys. Chem. C 2009, $113,6616$.

[24] R. Krishna, J. Phys. Chem. C 2009, 113, 19756.

[25] D. W. Keith, H.-D. Minh, J. K. Stolaroff, Clim. Change 2006, 74, 17.

[26] P. D. Vaidya, E. Y. Kenig, Chem. Eng. Technol. 2007, 30, 1467.

[27] G. Sartori, D. W. Savage, Ind. Eng. Chem. Fundam. 1983, 22, 239.

[28] A. Dibenedetto, M. Aresta, C. Fragale, M. Narracci, Green Chem. 2002, 4, 439.

[29] J. T. Yeh, H. W. Pennline, K. P. Resnik, Energy Fuels 2001, 15, 274.

[30] T. Mimura, T. Suda, I. Iwaki, A. Honda, H. Kumazawa, Chem. Eng. Commun. 1998, 170, 245.

[31] J. Johnson, Chem. Eng. News 2008, 86(March 3), 7.

[32] P. H. M. Feron, C. A. Hendriks, Oil Gas Sci. Technol. 2005, 60, 451.

[33] L. I. Eide, D. W. Bailey, Oil Gas Sci. Technol. 2005, 60, 475.

[34] Vattenfall's Project on CCS, http://www.vattenfall.com/www/ co2_en/co2_en/index.jsp.

[35] P. N. Dyer, R. E. Richards, S. L. Russeka, D. M. Taylor, Solid State Ionics 2000, 134, 21.

[36] M. M. Abu-Khader, Energy Sources Part A 2006, 28, 1261.

[37] M. Smiglak, A. Metlen, R. D. Rogers, Acc. Chem. Res. 2007, 40, 1182.

[38] J. L. Anthony, S. N. V. K. Aki, E. J. Maginn, J. F. Brennecke, Int. J. Environ. Technol. Manage. 2004, 4, 105.
[39] C. Cadena, J. L. Anthony, J. K. Shah, T. I. Morrow, J. F. Brennecke, E. J. Maginn, J. Am. Chem. Soc. 2004, 126, 5300.

[40] J. L. Anderson, J. K. Dixon, E. J. Maginn, J. F. Brenncke, J. Phys. Chem. B 2006, 110, 15059.

[41] E. D. Bates, R. D. Mayton, I. Ntai, J. H. Davis, J. Am. Chem. Soc. 2002, 124, 926.

[42] J. Tang, T. H. , W. Sun, M. Plancer, M. Radosz, Y. Shen, Chem. Commun. 2005, 3325.

[43] J. Tang, H. Tang, W. Sun, M. Radosz, Y. Shen, J. Polym. Sci. Part A 2005, 43, 5477.

[44] P. J. E. Harlick, A. Sayari, Ind. Eng. Chem. Res. 2006, 45, 3248.

[45] K. B. Lee, M. G. Beaver, H. S. Caram, S. Sircar, Ind. Eng. Chem. Res. 2008, 47, 8048.

[46] B. Feng, H. An, E. Tan, Energy Fuels 2007, 21, 426.

[47] T. Yamaguchi, T. Niitsuma, B. N. Nair, K. Nakagawa, J. Membr. Sci. 2007, 294, 16.

[48] E. Ochoa-Fernandez, H. K. Rusten, H. A. Jakobsen, M. Ronning, A. Holmen, D. Chen, Catal. Today 2005, 106, 41.

[49] C. T. Yavuz, B. D. Shinall, A. V. Iretskii, M. G. White, T. Golden, M. Atilhan, P. C. Ford, G. D. Stucky, Chem. Mater. 2009, 21,3473 .

[50] T. O. Nelson, L. J. Coleman, D. A. Green, R. P. Gupta, Energy Procedia: Greenhouse Gas Control Technologies 9, Proceedings of the 9th International Conference on Greenhouse Gas Control Technologies (GHGT-9), 16-20 November 2008, Washington, 2009, 1, 1305.

[51] R. V. Siriwardane, M.-S. Shen, E. P. Fisher, J. A. Poston, Energy Fuels 2001, 15, 279.

[52] K. T. Chue, J. N. Kim, Y. U. Yoo, S. H. Cho, R. T. Yang, Ind. Eng. Chem. Res. 1995, 34, 591.

[53] G. Maurin, P. L. Llewellyn, R. G. Bell, J. Phys. Chem. B 2005, 109, 16084.

[54] J. C. Hicks, J. H. Drese, D. J. Fauth, M. L. Gray, G. Qi, C. W. Jones, J. Am. Chem. Soc. 2008, 130, 2902.

[55] O. Leal, C. Bolivar, C. Ovalles, J. Garcia, Y. Espidel, Inorg. Chim. Acta 1995, 240, 183.

[56] R. V. Sirwardane, U.S. Patent 6,908,497 B1, 1, 2005.

[57] X. Xu, C. Song, B. G. Miller, A. W. Scaroni, Fuel Process. Technol. 2005, 86, 1457.

[58] S. Lee, T. P. Filburn, M. Gray, J.-W. Park, H.-J. Song, Ind. Eng. Chem. Res. 2008, 47, 7419.

[59] N. Hiyoshi, D. K. Yogo, T. Yashima, Chem. Lett. 2004, 33, 510.

[60] S. Mazumder, P. van Hemert, A. Busch, K.-H. Wolf, P. TejeraCuesta, Int. J. Coal Geol. 2006, 67, 267.

[61] C. A. Grande, A. E. Rodrigues, Int. J. Greenhouse Gas Control 2008, 2, 194.

[62] P. K. Thallapally, P. B. McGrail, J. L. Atwood, C. Gaeta, C. Tedesco, P. Neri, Chem. Mater. 2007, 19, 3355.

[63] P. K. Thallapally, P. B. McGrail, S. J. Dalgarno, H. T. Schaef, J. Tian, J. L. Atwood, Natutre Mater. 2008, 7, 146.

[64] H. Furukawa, O. M. Yaghi, J. Am. Chem. Soc. 2009, 131, 8876.

[65] R. Babarao, J. W. Jiang, Langmuir 2008, 24, 6270.

[66] R. Babarao, J. W. Jiang, J. Am. Chem. Soc. 2009, 131, 11417.

[67] S. R. Batten, R. Robson, Angew. Chem. 1998, 110, 1558; Angew. Chem. Int. Ed. 1998, 37, 1460.

[68] G. Férey, Dalton Trans. 2009, 4400.

[69] G. Férey, Chem. Soc. Rev. 2008, 37, 191.

[70] R. A. Fischer, C. Wöll, Angew. Chem. 2008, 120, 8285; Angew. Chem. Int. Ed. 2008, 47, 8164.

[71] S. R. Batten, S. M. Neville, D. R. Turner, Coordination Polymers: Design, Analysis and Application, Royal Society of Chemistry, Cambridge, 2008.

[72] D. Tanaka, S. Kitagawa, Chem. Mater. 2008, 20, 922.

[73] S. Kitagawa, R. Matsuda, Coord. Chem. Rev. 2007, 251, 2490.

[74] C. J. Kepert, Chem. Commun. 2006, 695.

[75] U. Mueller, M. Schubert, F. Teich, H. Puetter, K. SchierleArndt, J. Pastre, J. Mater. Chem. 2006, 16, 626. 
[76] D. Bradshaw, J. B. Claridge, E. J. Cussen, T. J. Prior, M. J. Rosseinsky, Acc. Chem. Res. 2005, 38, 273.

[77] S. Kitagawa, R. Kitaura, S. Noro, Angew. Chem. 2004, 116, 2388; Angew. Chem. Int. Ed. 2004, 43, 2334.

[78] M. J. Rosseinsky, Microporous Mesoporous Mater. 2004, 73, 15.

[79] A. Stein, Adv. Mater. 2003, 15, 763.

[80] S. Natarajan, S. Mandal, Angew. Chem. 2008, 120, 4876; Angew. Chem. Int. Ed. 2008, 47, 4798.

[81] O. M. Yaghi, M. O'Keeffe, N. W. Ockwig, H. K. Chae, M Eddaoudi, J. Kim, Nature 2003, 423, 705.

[82] M. Eddaoudi, D. B. Moler, H. Li, B. Chen, T. M. Reineke, M. O’Keeffe, O. M. Yaghi, Acc. Chem. Res. 2001, 34, 319.

[83] D. J. Tranchemontagne, Z. Ni, M. O'Keeffe, O. M. Yaghi, Angew. Chem. 2008, 120, 5214; Angew. Chem. Int. Ed. 2008, 47, 5136.

[84] M. O'Keeffe, M. A. Peskov, S. J. Ramsden, O. M. Yaghi, Acc. Chem. Res. 2008, 41, 1782.

[85] N. L. Rosi, J. Kim, M. Eddaoudi, B. Chen, M. O'Keeffe, O. M Yaghi, J. Am. Chem. Soc. 2005, 127, 1504

[86] M. Eddaoudi, J. Kim, N. Rosi, D. Vodak, J. Wachter, M. O’Keeffe, O. M. Yaghi, Science 2002, 295, 469.

[87] A. G. Wong-Foy, A. J. Matzger, O. M. Yaghi, J. Am. Chem. Soc. 2006, 128, 3494.

[88] A. R. Millward, O. M. Yaghi, J. Am. Chem. Soc. 2005, 127, 17998.

[89] Y. E. Cheon, M. P. Suh, Chem. Eur. J. 2008, 14, 3961.

[90] Z. Zhao, Z. Li, Y. S. Lin, Ind. Eng. Chem. Res. 2009, 48, 10015.

[91] K. S. Walton, A. R. Millward, D. Dubbeldam, H. Frost, J. J. Low, O. M. Yaghi, R. Q. Snurr, J. Am. Chem. Soc. 2008, 130, 406

[92] M. Xue, Y. Liu, R. M. Schaffino, S. Xiang, X. Zhao, G.-S. Zhu, S.-L. Qui, B. Chen, Inorg. Chem. 2009, 48, 4649.

[93] S. R. Miller, P. A. Wright, T. Devic, C. Serre, G. Ferey, P. L. Llewellyn, R. Denoyel, L. Gaberova, Y. Filinchuk, Langmuir 2009, 25, 3618 .

[94] A. Comotti, S. Bracco, P. Sozzani, S. Horike, R. Matsuda, J. Chen, M. Takata, Y. Kubota, S. Kitagawa, J. Am. Chem. Soc. 2008, 130, 13664

[95] B.-Q. Ma, K. L. Mulfort, J. T. Hupp, Inorg. Chem. 2005, 44, 4912.

[96] K. L. Mulfort, J. T. Hupp, J. Am. Chem. Soc. 2007, 129, 9604

[97] Y. S. Bae, K. L. Mulfort, H. Frost, P. Ryan, S. Punnathanam, L. J. Broadbelt, J. T. Hupp, R. Q. Snurr, Langmuir 2008, 24 8592 .

[98] A. Phan, C. J. Doonan, F. J. Uribe-Romo, C. B. Knobler, M. O'Keeffe, O. M. Yaghi, Acc. Chem. Res. 2010, 43, 58.

[99] R. Banerjee, A. Phan, B. Wang, C. Knobler, H. Furukawa, M. O'Keeffe, O. M. Yaghi, Science 2008, 319, 939.

[100] K. S. Park, Z. Ni, A. P. Cote, J. Y. Choi, R. Huang, F. J. UribeRomo, H. K. Chae, M. O'Keeffe, O. M. Yaghi, Proc. Natl. Acad. Sci. USA 2006, 103, 10186.

[101] H. Hayashi, A. P. Cote, H. Furukawa, M. O'Keeffe, O. M. Yaghi, Nat. Mater. 2007, 6, 501.

[102] P. Küsgens, M. Rose, I. Senkovska, H. Fröde, A. Henschel, S. Siegle, K. Kaskel, Microporous Mesoporous Mater. 2009, 120 , 325.

[103] S. S.-Y. Chui, S. M.-F. Lo, J. P. H. Charmant, A. G. Orpen, I. D. Williams, Science 1999, 283, 1148

[104] Q. M. Wang, D. Shen, M. Bülow, M. L. Lau, S. Deng, F. R. Fitch, N. O. Lemcoff, J. Semanscin, Microporous Mesoporous Mater. 2002, 55, 217.

[105] P. Chowdhury, C. Bikkina, D. Meister, F. Dreisbach, S. Gumma, Microporous Mesoporous Mater. 2009, 117, 406.

[106] Z. Liang, M. Marshall, A. L. Chaffee, Energy Fuels 2009, 23, 2785.
[107] S. Bordiga, L. Regli, F. Bonino, E. Groppo, C. Lamberti, B. Xiao, P. S. Wheatley, R. E. Morris, A. Zecchina, Phys. Chem. Chem. Phys. 2007, 9, 2676.

[108] A. O. Yazaydın, A. I. Benin, S. A. Faheem, P. Jakubczak, J. J. Low, R. R. Willis, R. Q. Snurr, Chem. Mater. 2009, 21, 1425.

[109] P. L. Llewellyn, S. Bourrelly, C. Serre, A. Vimont, M. Daturi, L. Hamon, G. Weireld, J.-S. Chang, D.-Y. Hong, Y. K. Hwang, S. H. Jhung, G. Ferey, Langmuir 2008, 24, 7245.

[110] S. R. Miller, G. M. Pearce, P. A. Wright, F. Bonino, S. Chavan, S. Bordiga, I. Margiolaki, N. Guillou, G. Ferey, S. Bourrelly, P. L. Llewellyn, J. Am. Chem. Soc. 2008, 130, 15967.

[111] P. D. C. Dietzel, V. Besikiotis, R. Blom, J. Mater. Chem. 2009, 19,7362

[112] S. R. Caskey, A. G. Wong-Foy, A. Matzger, J. Am. Chem. Soc. 2008, 130, 10870 .

[113] D. Britt, H. Furukawa, B. Wang, T. G. Glover, O. M. Yaghi, Proc. Natl. Acad. Sci. USA 2009, 106, 20637.

[114] Y.-S. F. Bae, O. K. Farha, A. M. Spokoyny, C. A. Mirkin, J. T. Hupp, R. Q. Snurr, Chem. Commun. 2008, 4135.

[115] Y. E. Cheon, M. P. Suh, Chem. Commun. 2009, 2296.

[116] B. Chen, S. Ma, E. J. Hurtado, E. B. Lobkovsky, H.-C. Zhou, Inorg. Chem. 2007, 46, 8490.

[117] L. Bastin, P. S. Barcia, E. J. Hurtado, J. A. C. Silva, A. E. Rodrigues, B. Chen, J. Phys. Chem. C 2008, 112, 1575.

[118] Y. E. Cheon, J. Park, M. P. Suh, Chem. Commun. 2009, 5436.

[119] S. Bourrelly, P. L. Llewellyn, C. Serre, F. Millange, L. Loiseau, G. Férey, J. Am. Chem. Soc. 2005, 127, 13519.

[120] P. L. Llewellyn, S. Bourrelly, C. Serre, Y. Filinchuk, G. Ferey, Angew. Chem. 2006, 118, 7915; Angew. Chem. Int. Ed. 2006, 45, 7751

[121] S. Galli, N. Masciocchi, G. Tagliabue, A. Sironi, J. A. R. Navarro, J. M. Salas, L. Mendez-Linan, M. Domingo, M. Perez, E. Barea, Chem. Eur. J. 2008, 14, 9890.

[122] H.-S. Choi, M. P. Suh, Angew. Chem. 2009, 121, 6997; Angew. Chem. Int. Ed. 2009, 48, 6865.

[123] Y.-S. Bae, O. K. Farha, J. T. Hupp, R. Q. Snurr, J. Mater. Chem. 2009, 19, 2131

[124] E. Neofotistou, C. D. Malliakas, P. N. Trikalitis, Chem. Eur. J. 2009, 15, 4523

[125] S. Couck, J. F. M. Denayer, G. V. Baron, T. Remy, J. Gascon, F. Kapteijn, J. Am. Chem. Soc. 2009, 131, 6326.

[126] B. Arstad, H. Fjellvag, K. O. Kongshaug, O. Swang, R. Blom, Adsorption 2008, 14, 755 .

[127] A. Demessence, D. M. D'Alessandro, M. L. Foo, J. R. Long, J. Am. Chem. Soc. 2009, 131, 8784 .

[128] F. Dreisbach, R. Staudt, J. U. Keller, Adsorption 1999, 5, 215.

[129] P. D. C. Dietzel, R. E. Johnsen, H. Fjellvag, S. Bordiga, E. Groppo, S. Chavan, R. Blom, Chem. Commun. 2008, 5125.

[130] O. K. Farha, A. M. Spokoyny, K. L. Mulfort, S. Galli, J. T. Hupp, C. A. Mirkin, Small 2009, 5, 1727.

[131] S. Horike, S. Shimomura, S. Kitagawa, Nat. Chem. 2009, 1, 695.

[132] P. K. Thallapally, J. Tian, M. R. Kishan, C. A. Fernandez, S. J. Dalgarno, P. B. McGrail, J. E. Warren, J. L. Atwood, J. Am. Chem. Soc. 2008, 130, 16842.

[133] A. Vimont, A. Travert, P. Bazin, J.-C. Lavalley, M. Daturi, C. Serre, G. Ferey, S. Bourrelly, P. L. Llewellyn, Chem. Commun. 2007, 3291.

[134] C. Serre, S. Bourrelly, A. Vimont, N. A. Ramsahye, G. Maurin, P. L. Llewellyn, M. Daturi, Y. Filinchuk, O. Leynaud, P. Barnes, G. Ferey, Adv. Mater. 2007, 19, 2246.

[135] N. A. Ramsahye, G. Maurin, S. Bourrelly, P. Llewellyn, T. Loiseau, G. Ferey, Phys. Chem. Chem. Phys. 2007, 9, 1059.

[136] N. A. Ramsahye, G. Maurin, S. Bourrelly, P. L. Llewellyn, T. Loiseau, C. Serre, G. Ferey, Chem. Commun. 2007, 3261.

[137] N. A. Ramsahye, G. Maurin, S. Bourrelly, P. L. Llewellyn, C. Serre, T. Loiseau, T. Devic, G. Ferey, J. Phys. Chem. C 2008, 112,514 
[138] L. Hamon, P. L. Llewellyn, T. Devic, A. Ghoufi, G. Clet, V. Guillerm, G. D. Pirngruber, G. Maurin, C. Serre, G. Driver, W. van Beek, E. Jolimaitre, A. Vimont, M. Daturi, G. Ferey, J. Am. Chem. Soc. 2009, 131, 17490.

[139] H. Kanoh, A. Kondo, H. Noguchi, H. Kajiro, A. Tohdoh, Y. Hattori, W.-C. Xu, M. Inoue, T. Siugiura, K. Morita, T. Ohba, K. Kaneko, J. Colloid Interface Sci. 2009, 334, 1.

[140] A. Kondo, A. Chinen, H. Kajiro, T. Nakagawa, K. Kato, M. Takata, Y. Hattori, F. Okino, T. Ohba, K. Kaneko, H. Kanoh, Chem. Eur. J. 2009, 15, 7549.

[141] S. Ma, D. Sun, X.-S. Wang, H.-C. Zhou, Angew. Chem. 2007, 119, 2510; Angew. Chem. Int. Ed. 2007, 46, 2458.

[142] B. Wang, A. P. Cote, H. Furukawa, M. O'Keeffe, O. M. Yaghi, Nature 2008, 453, 207.

[143] S. Ma, X.-S. Wang, E. S. Manis, C. D. Collier, H.-C. Zhou, Inorg. Chem. 2007, 46, 3432.

[144] K. K. Tanabe, Z. Wang, S. M. Cohen, J. Am. Chem. Soc. 2008, $130,8508$.

[145] F. Salles, H. Jobic, A. Ghoufi, P. L. Llewellyn, C. Serre, S. Bourrelly, G. Ferey, G. Maurin, Angew. Chem. 2009, 121, 8485; Angew. Chem. Int. Ed. 2009, 48, 8335.

[146] D. Saha, S. Deng, J. Chem. Eng. Data 2009, 54, 2245.

[147] D. Saha, Z. Wei, S. Deng, Int. J. Hydrogen Energy 2008, 33, 7479.

[148] S. Keskin, J. Liu, J. K. Johnson, D. S. Sholl, Langmuir 2008, 24, 8254.

[149] V. Krungleviciute, K. Lask, A. D. Migone, J.-Y. Lee, J. Li, AIChE J. 2008, 54, 918.

[150] D. Frenkel, B. Smit, Understanding Molecular Simulations: From Algorithms to Applications, 2nd ed., Academic Press, San Diego, 2002.

[151] B. Smit, T. L. M. Maesen, Chem. Rev. 2008, 108, 4125.

[152] G. Férey, C. Serre, Chem. Soc. Rev. 2009, 38, 1380.

[153] C. Serre, F. Millange, C. Thouvenot, M. Nogues, G. Marsolier, D. Louer, G. Ferey, J. Am. Chem. Soc. 2002, 124, 13519.

[154] Y. Liu, J. H. Her, A. Dailly, A. J. Ramirez-Cuesta, D. A Neumann, C. M. Brown, J. Am. Chem. Soc. 2008, 130, 11813.

[155] D. Dubbeldam, R. Krishna, R. Q. Snurr, J. Phys. Chem. C 2009, 113, 19317.

[156] F. Salles, A. Ghoufi, G. Maurin, R. G. Bell, C. MellotDraznieks, G. Ferey, Angew. Chem. 2008, 120, 8615; Angew. Chem. Int. Ed. 2008, 47, 8487.

[157] D. S. Coombes, F. Cora, C. Mellot-Draznieks, R. G. Bell, J. Phys. Chem. C 2009, 113, 544

[158] F. X. Coudert, C. Mellot-Draznieks, A. H. Fuchs, A. Boutin, J. Am. Chem. Soc. 2009, 131, 11329.

[159] A. Garcia-Sanchez, C. O. Ania, J. B. Parra, D. Dubbeldam, T. J. H. Vlugt, R. Krishna, S. Calero, J. Phys. Chem. C 2009, 113, 8814.

[160] R. B. Rankin, J. C. Liu, A. D. Kulkarni, J. K. Johnson, J. Phys. Chem. C 2009, 113, 16906.

[161] J. I. Siepmann, S. Karaborni, B. Smit, J. Am. Chem. Soc. 1993, 115,6454

[162] J. L. Belof, A. C. Stern, B. Space, J. Chem. Theory Comput. 2008, 4, 1332 .

[163] A. Torrisi, C. Mellot-Draznieks, R. G. Bell, J. Chem. Phys. 2009, 130, 194703.

[164] K. Sillar, A. Hofmann, J. Sauer, J. Am. Chem. Soc. 2009, 131, 4143.

[165] B. Liu, B. Smit, Langmuir 2009, 25, 5918.

[166] C. Mellot-Draznieks, J. Mater. Chem. 2007, 17, 4348.

[167] T. Düren, Y. S. Bae, R. Q. Snurr, Chem. Soc. Rev. 2009, 38, 1237.

[168] A. J. Fletcher, K. M. Thomas, M. J. Rosseinsky, J. Solid State Chem. 2005, 178, 2491.

[169] Q. Y. Yang, C. L. Zhong, Langmuir 2009, 25, 2302.

[170] R. Babarao, J. W. Jiang, Energy Environ. Sci. 2008, 1, 139.

[171] R. Krishna, J. M. van Baten, Langmuir 2010, 26, 3981.
[172] R. Krishna, J. M. van Baten, Langmuir 2010, 26, 8450.

[173] R. Krishna, J. M. van Baten, Chem. Eng. J. 2007, 133, 121.

[174] Q. Yang, C. Xue, C. Zhong, J.-F. Chen, AIChE J. 2007, 53, 2832.

[175] A. Martin-Calvo, E. Garcia-Perez, J. M. Castillo, S. Calero, Phys. Chem. Chem. Phys. 2008, 10, 7085.

[176] S. Keskin, D. S. Sholl, Ind. Eng. Chem. Res. 2009, 48, 914.

[177] S. Keskin, D. S. Sholl, J. Phys. Chem. Lett. C 2007, 111, 14055.

[178] D. Sholl, S. Keskin, S. E. Jee, H. Chen, Abstracts of Papers, 234th ACS National Meeting, Boston, August 19-23 2007, FUEL216.

[179] S. Keskin, J. Liu, J. K. Johnson, D. S. Sholl, Microporous Mesoporous Mater. 2009, 125, 101.

[180] C. A. Scholes, S. E. Kentish, G. W. Stevens, Recent Pat. Chem. Eng. 2008, 1, 52

[181] L. Robeson, J. Membr. Sci. 1991, 62, 165.

[182] L. Zhang, I.-S. Park, K. Shqau, W. S. W. Ho, H. Verweij, JOM 2009, 61(April), 61.

[183] Carbon Capture and its Storage: an Integrated Assessment (Eds.: S. Shackley, C. Gough), Aldershot, Ashgate, 2006, p. 313.

[184] M. A. Carreon, S. Li, J. L. Falconer, R. D. Noble, J. Am. Chem. Soc. 2008, 130, 5412.

[185] H. Guo, G. Zhu, I. J. Hewitt, S. Qui, J. Am. Chem. Soc. 2009, $131,1646$.

[186] Y. Liu, Z. Ng, E. A. Khan, H.-K. Jeong, C. Ching, Z. Lai, Microporous Mesoporous Mater. 2009, 118, 296.

[187] Y.-S. Li, F.-Y. Liang, H. Bux, A. Feldhoff, W.-S. Yang, J. Caro, Angew. Chem. 2010, 122, 558; Angew. Chem. Int. Ed. 2010, 49, 548.

[188] N. B. McKeown, P. M. Budd, Chem. Soc. Rev. 2006, 35, 675.

[189] V. Abetz, T. Brinkmann, M. Dijkstra, K. Ebert, D. Fritsch, K. Ohlrogge, D. Paul, K.-V. Peinemann, S. Pereira-Nunes, N. Scharnagi, M. Schossig, Adv. Eng. Mater. 2006, 8, 328.

[190] C. E. Powell, G. G. Qiao, J. Membr. Biol. 2006, 279, 1.

[191] R. W. Baker, K. Lokhandwala, Ind. Eng. Chem. Res. 2008, 47, 2109.

[192] J. Germain, J. M. J. Frechet, F. Svec, J. Mater. Chem. 2007, 17, 4989.

[193] J. Germain, J. M. J. Fréchet, F. Svec, PMSE Preprints 2007, 97, 272.

[194] J. Germain, J. Hradil, J. M. J. Frechet, F. Svec, Chem. Mater. 2006, 18,4430 .

[195] J. Germain, J. M. J. Frechet, F. Svec, Chem. Mater. 2008, 20, 7069.

[196] J. Zou, W. S. W. Ho, J. Membr. Sci. 2006, 286, 310.

[197] Y. Zhang, I. H. Musselman, J. P. Ferraris, K. J. Balkus, J. Membr. Sci. 2008, 313, 170.

[198] S. Choi, J. Coronas, E. Jordan, W. Oh, S. Nair, F. Onorato, D. F. Shantz, M. Tsapatsis, Angew. Chem. 2008, 120, 562; Angew. Chem. Int. Ed. 2008, 47, 552.

[199] R. Quinn, J. B. Appleby, G. P. Pez, J. Membr. Sci. 1995, 104, 139.

[200] J. E. Bara, C. J. Gabriel, E. S. Hatakeyamaa, T. K. Carlisle, S. Lessmann, R. D. Noble, D. L. Gin, J. Membr. Sci. 2008, 321, 3.

[201] C. Myers, H. Pennline, D. Luebke, J. Ilconich, J. K. Dixon, E. J. Maginn, J. F. Brennecke, J. Membr. Sci. 2008, 322, 28.

[202] J. Ilconich, C. Myers, H. Pennline, D. Luebke, J. Membr. Sci. 2007, 298, 41.

[203] E. Favre, J. Membr. Sci. 2007, 294, 50.

[204] C. Stewart, M.-A. Hessami, Energy Convers. Manage. 2005, 46, 403.

[205] P. Linga, R. Kumar, P. Englezos, J. Hazard. Mater. 2007, 149, 625.

[206] R. Kumar, P. Englezos, I. Moudrakovski, J. A. Ripmeester, AIChE J. 2009, 55, 1584.

[207] R. Kumar, P. Linga, J. A. Ripmeester, P. Englezos, J. Environ. Eng. 2009, 411.

[208] B. Smit, R. Krishna, Chem. Eng. Sci. 2003, 58, 557. 